\title{
Global snow mass measurements and the effect of stratigraphic detail on inversion of microwave brightness temperatures
}

Article

Accepted Version

Richardson, M., Davenport, I. and Gurney, R. (2013) Global snow mass measurements and the effect of stratigraphic detail on inversion of microwave brightness temperatures. Surveys in Geophysics, 35 (3). pp. 785-812. ISSN 0169-3298 doi: https://doi.org/10.1007/s10712-013-9263-x Available at https://centaur.reading.ac.uk/36201/

It is advisable to refer to the publisher's version if you intend to cite from the work. See Guidance on citing.

Published version at: http://link.springer.com/article/10.1007\%2Fs10712-013-9263-x

To link to this article DOI: http://dx.doi.org/10.1007/s10712-013-9263-x

Publisher: Springer Netherlands

All outputs in CentAUR are protected by Intellectual Property Rights law, including copyright law. Copyright and IPR is retained by the creators or other copyright holders. Terms and conditions for use of this material are defined in the End User Agreement.

www.reading.ac.uk/centaur 
Central Archive at the University of Reading

Reading's research outputs online 


\section{Global Snow Mass Measurements and the Effect of Stratigraphic Detail on} 3 Inversion of Microwave Brightness Temperatures

4 Mark Richardson", Ian Davenport, Robert Gurney

5 Department of Meteorology, University of Reading, UK

6 Abstract Snow provides large seasonal storage of freshwater, and information about the distribution of snow mass as Snow Water Equivalent (SWE) is important for hydrological planning and detecting climate change impacts. Large regional disagreements remain between estimates from reanalyses, remote sensing and modelling. Assimilating passive microwave information improves SWE estimates in many regions but the assimilation must account for how microwave scattering depends on snow stratigraphy. Physical snow models can estimate snow stratigraphy, but users must consider the computational expense of model complexity versus acceptable errors. Using data from the National Aeronautics and Space Administration Cold Land Processes Experiment (NASA CLPX) and the Helsinki University of Technology (HUT) microwave emission model of layered snowpacks, it is shown that simulations of the brightness temperature difference between $19 \mathrm{GHz}$ and $37 \mathrm{GHz}$ vertically polarised microwaves are consistent with Advanced Microwave Scanning Radiometer-Earth Observing System (AMSR-E) and Special Sensor Microwave Imager (SSM/I) retrievals once known stratigraphic information is used. Simulated brightness temperature differences for an individual snow profile depend on the provided stratigraphic detail. Relative to a profile defined at the $10 \mathrm{~cm}$ resolution of density and temperature measurements, the error introduced by simplification to a single layer of average properties increases approximately linearly with snow mass. If this brightness temperature error is converted into SWE using a traditional retrieval method then it is equivalent to $\pm 13 \mathrm{~mm} \mathrm{SWE}$ (7\% of total) at a depth of $100 \mathrm{~cm}$. This error is reduced to $\pm 5.6 \mathrm{~mm} \mathrm{SWE} \mathrm{(3 \%} \mathrm{of}$ total) for a two-layer model.

Keywords snow mass, snow grain size, remote sensing, microwave radiometry, hydrology

Corresponding Author: M. Richardson, ESSC Harry Pitt Building, 3 Earley Gate, University of phone: +44 1183785216 fax: +44 1183786413 


\section{Introduction}

32 Snow is extremely important hydrologically, with more than one-sixth of the global population situated in areas where snow precipitation is greater than half of annual runoff (Barnett et al., 2005). Snow affects both timing and quantity of runoff as well as the surface energy balance (Budyko, 1958) and atmospheric chemistry (Dominé \& Shepson, 2002).

Currently, remote sensing products exist for snow covered area (SCA), albedo, grain-size, surface contaminants, melt and Snow Water Equivalent (SWE). Measurements of snow surface properties such as SCA are regularly used (e.g. Brown \& Mote, 2009; Dye, 2002; Frei et al., 2003) and generally have more well-characterised uncertainties (Hall \& Riggs, 2007; Rittger et al., 2013) than estimates of bulk properties such as SWE.

Measurement of surface properties has allowed the identification of snow-season duration (Dye, 2002), surface melt (Koskinen et al., 1997) and a determination of snow's contribution to radiative feedback in response to warming (Flanner et al., 2011). In terms of hydrological relevance, Painter et al., 2012 developed a Moderate Resolution Imaging Spectroradiometer (MODIS) algorithm for determining radiative forcing from impurities in near-surface snow. When realistic values of these radiative forcings were included in analysis of snow in south-western Colorado, it was estimated that the impurities reduced snow cover duration by 21 to 51 days, increased peak outflow, changed the runoff profile and reduced total seasonal runoff (Skiles et al., 2012).

Despite the successes of surface measurements there remain large uncertainties in global estimates of SWE, with regional disagreements between products derived from remote sensing, General Circulation Models (GCMs) and reanalyses (Clifford, 2010).

This study reviews continental-scale SWE products and describes the key techniques and their relative strengths, including the assimilation of remotely sensed passive microwave (PM) observations. A recent product which assimilates PM, Globsnow (Takala et al., 2011), is described in detail as it has been suggested as a suitable product for validation of Land Surface Models (LSMs, (Hancock et al., 2013)).

The assimilation of PM observations requires an observation operator which converts the state vector of snow properties into a vector of observable microwave brightness temperatures. In the case of Globsnow, the snow is described by density, grain size and snow depth of a single layer. The observation operator is the Helsinki University of Technology (HUT) radiative transfer model

61 (Pulliainen et al., 1999) which produces a brightness temperature difference between two PM 62 channels, $\Delta T_{B}$, for comparison with satellite retrievals. 
Although Globsnow assumes a single homogeneous layer, snowpacks typically consist of multiple layers that often feature complex stratigraphy which affects the radiative transfer. The current Globsnow approach neglects this in both the radiative transfer simulation and in calculating the weighting function that determines the size of the PM-driven update to the forecast.

Globsnow's performance might be improved by the relaxation of the 1-layer assumption, and here the effect of this relaxation on simulated $\Delta T_{B} \mathrm{~s}$ is assessed based on realistic snow profiles obtained from the snowpits of the National Aeronautics and Space Administration Cold Land Processes Experiment (NASA CLPX).

Section 2 reviews the historical methods of snow mass estimation, including separate estimates from snow models, ground stations and PM. Section 3 introduces the principles behind assimilation of passive microwaves and details Globsnow, identifying its simplified snow stratigraphy as a possible source of error and suggesting that layering might be included in a future scheme.

Section 4 describes the experiments which attempt to assess the effect of realistic snow layering on radiative transfer. Coincident satellite PM measurements are compared with HUT simulations at CLPX, confirming that HUT simulations are close to observed values. The effect of including or neglecting detailed snow layering is assessed by comparing $\Delta T_{B}$ simulations when snowpits are resampled to different layering profiles. Profiles include between 1- and 5 layers, along with an Nlayer case where layers are prescribed based on the snowpit measurement resolution. The N-layer case is taken as truth, and the difference in simulated $\Delta T_{B}$ f for fewer-layer models relative to this truth allows statistical estimation of the bias and variance introduced through simplification of stratigraphy to fewer layers, which are reported as a function of snow depth and number of layers.

The results are related in Section 5 and discussed in Section 6 where it is indicated that neglect of statigraphy may mean that Globsnow has unaccounted variance in its assimilation step. The results have relevance to a user who may use these to calculate variance introduced due to simplified stratigraphy, or alternatively may choose an optimal layering structure based on criteria of computational expense and acceptable levels of variance. However, it is cautioned that these results are only derived for snow typical of that present during CLPX.

\section{Current Snow Mass Estimation}

\subsection{General Circulation Models and Reanalyses}

Without the global coverage of space-based remote sensing, alternative methods of snow mass estimation have relied on a combination of models and observations. Coupled GCMs are a modelling approach and have been used to estimate SWE climatologies for current conditions, and the spatial 
and temporal components of these climatologies have been explored by Clifford (2010) and Roesch (2006) among others.

However, due to the chaotic nature of the system, fully coupled models are only capable of estimating climatology and in order to produce a time series corresponding to the real world realisation of weather, regular assimilation of observational data is required.

As such a number of reanalysis products have been produced, coupling LSMs which simulate the snow cover with an atmospheric model. These reanalyses regularly assimilate observations of both the atmosphere and the land surface, although no fully-coupled land-atmosphere reanalysis yet assimilates microwave radiances for the purpose of snow mass estimation. Instead, in-situ synoptic station measurements of snow depth and estimates of SCA based on satellite data are used.

The full details of these reanalyses and their assimilation schemes is beyond the scope of this paper, the reader is directed to the references in Table 1 which details selected reanalyses and other gridded products which offer snow mass or snow depth.

A number of assessments of reanalysis performance in terms of snow variables have been undertaken. Khan \& Holko (2009) noted that reanalyses performed well in much of the Aral Sea Basin, although there were underestimates of snow depth and SWE in mountainous areas. Betts et al. (2009) determined that both the European Centre for Medium Range Weather Forecasts (ECMWF) 40 year and Interim Reanalyses (ERA-40, ERA-Interim) suffer from early snow melt out. Meanwhile, Clifford (2010) reported the spatial and temporal characteristics of different approaches to snow mass estimation in more detail, and that the potential for future improvements remains clear. Improved modelling is one opportunity, with Salzmann \& Mearns (2012) comparing SWE modelled by a number of higher resolution Regional Climate Models (RCMs) with snow telemetry observations in the Upper Colorado River Basin. Though the RCMs remained too warm and dry with too little SWE, their simulations better matched observations than the original reanalysis. However, biases remained even with these more computationally expensive models.

\subsection{Products which prioritise snow}

\subsubsection{Surface observations only}

Outside of reanalyses which attempt to produce complete time series of land and atmosphere properties, a number of snow specific products have been developed. The simplest approach is to grid weather station snow depth records as performed by Dyer and Mote (2006) in North America and Kitaev et al. (2002) in the Former Soviet Union (FSU). In Kitaev et al.'s work, station number varied from 2 to 25 per $3^{\circ} \times 5^{\circ}$ grid square and snow's spatial variability within such areas means that large uncertainties are associated with such sparse measurements. Chang et al. (2005) estimated that across 
the Northern Great Plains, 10 measurements were required per $1^{\circ}$ cell to reduce sampling error of snow depth to $\pm 5 \mathrm{~cm}$, equivalent to a station density between 6 and 75 times higher than available to Kitaev et al. Furthermore, the sampling distribution of snow stations was found by Brasnett (1999) to be biased to low elevations.

Post-hoc assessment of snow mass is possible using river discharge data, although this approach suffers from large uncertainties due to unknowns related to inter-annual terrestrial water storage, periods of river-ice and non-snow contributions. This approach has allowed attempts to test seasonal estimates of snow mass in some basins (e.g. Grippa et al., 2005; Rawlins et al., 2007; Yang et al., 2007) and to provide evidence in conjunction with other snow products for intensification of the Arctic hydrological cycle in response to global warming since 1950 (Rawlins, et al., 2010).

\subsubsection{Land Surface Models assimilating in-situ observations}

Simple areal averaging of snow depth observations cannot account for variation in areas between point measurements, which can be driven by different elevation, meteorological regime or land surface category. LSMs featuring a snow component are in principle able to account for these effects and furthermore these models may assimilate measured snow depths when available to improve the analysis.

Brown et al. (2003) used the Canadian Meteorological Centre's analysis scheme developed by Brasnett (1999) to generate a gridded time series of North American snow depth and SWE. A simple snow model was driven by meteorological data from the ECMWF 15-year Reanalysis (ERA-15), with assimilation of 8,000 snow measurements per day from the U.S. and Canada. This method relies on relatively intensive daily measurements, for which the authors noted that availability drops off rapidly poleward of $55^{\circ} \mathrm{N}$.

A global estimate is published by the ECMWF using a similar approach and a summary and assessment is provided by Drusch et al. (2004). They note that the observational stations are biased towards lower latitudes and lower elevations, and that without assimilating remotely sensed information on Snow Covered Area there are disagreements between the estimated snow covered areas, and from the Interactive Multisensor Snow and Ice Mapping System (IMS) described in Ramsay (1998).

\subsection{Remote sensing of snow mass}

The approaches discussed in Sections 2.1 and 2.2 have been used to estimate snow climatologies and detect climatic changes, but their continued reliance on intensive in-situ measurements leaves large 
uncertainties in some regions. This justifies continued development of remote sensing products which can provide global coverage for improved estimates of snow mass where station density is insufficient.

Beginning with the work of Frappart et al. (2006) and continuing with Niu et al. (2007) and others, the Gravity Recovery and Climate Experiment (GRACE) gravimetry mission has been used to estimate snow mass based on observing changes in Earth's gravitational field. GRACE responds directly to gravitational changes, suggesting that it should be well suited to retrievals of deep snow or snow in forested areas where traditional remote sensing has to see 'through' the trees. However, further modelling is required to control for other changes in mass of the land surface associated with, for example, other forms of terrestrial water storage. Additionally, GRACE is not suitable for high resolution measurement with Frappart et al. (2006)'s reported resolution being $660 \mathrm{~km}$. Finally, it is not yet appropriate for assessing long term changes as the GRACE satellites were only launched in 2002.

As such, efforts for the remote sensing of snow mass have typically focussed on the passive microwave regime, using frequencies near $19 \mathrm{GHz}$ and $37 \mathrm{GHz}$, for which there has been continuous near-global coverage since the launch of the Scanning Multichannel Microwave Radiometer (SMMR) on Nimbus-7 in late 1978. Many snow products typically utilise the Special Sensor Microwave Imagers (SSM/I) (e.g. Tedesco et al. 2004a) and/or the Advanced Microwave Scanning RadiometerEarth Observing System (AMSR-E) (Tedesco et al., 2004b).

When observing a typical snowpack, the majority of radiation measured at these wavelengths will have originated from the ground surface, with scattering within the snow the dominant loss mechanism. This scattering is frequency dependent and increases with the quantity of snow, allowing a determination of SWE from the difference between the brightness temperatures in these two channels.

Figure 1 shows simulations of the brightness temperatures over a snowpack at $18.7 \mathrm{GHz}$ and 36.5 $\mathrm{GHz}$ horizontal polarisations viewed at $53^{\circ}$. Snow is assumed to be a homogeneous single layer with properties based on those typical of Colorado snowpacks of under $120 \mathrm{~cm}$ depth discussed in Davenport et al. (2012). As the amount of snow increases up to $500 \mathrm{~mm}$ SWE, the brightness temperature at both frequencies falls, but it falls more quickly at the higher frequency.

By considering the difference in brightness temperatures between the two frequencies, the effect of absolute temperature change is reduced and this led to the simplest approach to SWE retrieval, often called the Chang Algorithm, which was originally developed for SMMR (Chang et al. 1987), a general variant of which is: 
194 Where $A$ and $B$ are constants depending on the exact frequency of the channel and snow properties 195 (Armstrong \& Brodzik, 2000), $T_{B} 19 H$ and $T_{B} 37 H$ are the recorded brightness temperatures at the 196 available channels nearest $19 \mathrm{GHz}$ and $37 \mathrm{GHz}$ horizontal polarisation. Figure 1 shows this equation 197 fit to the first $100 \mathrm{~mm} \mathrm{SWE}$, and for this snow the values are $A=2.54 \mathrm{~mm}_{\mathrm{SwE}} \mathrm{K}^{-1}$ and $B=3 \mathrm{~K}$.

198 Passive microwave measurements offer the advantage of being largely independent of illumination conditions, precipitation or cloud cover, allowing night time measurements when temperatures are likely to be lower and moisture within the snow is more likely to have refrozen. However, the range of values which can be reliably sensed is limited at the lower end by sensor precision, and at higher values of SWE the signal saturates (displayed in Figure 1 as a flattening of the solid line). The limiting value of this saturation depends on snow properties, and was reported by Foster et al., 2005 to be $0.8 \mathrm{~m}$ depth.

In reality the saturation level depends on the snow properties and on the definition of saturation. For the snow properties shown in Figure 1, saturation could be determined as the point at which the SWE inverted from the brightness temperature difference using a linear fit diverges by more than $10 \%$ away from the true value. In this case, this occurs at a SWE of $143 \mathrm{~mm}$, equivalent to a depth of $79.4 \mathrm{~cm}$ which matches well with the value provided by Foster et al. (2005).

An alternative definition of saturation accepts that a more complicated function may be used to map observed brightness temperature difference to SWE. Under this definition saturation is the point at which the signal is no longer sufficiently sensitive to SWE. This can be determined as the point at which error in inverted SWE, $\triangle S W E$ exceeds some acceptable value $\Delta S W E_{a}$. The sensitivity of brightness temperature difference $\Delta T_{B}=T_{B} 19 H-T_{B} 37 H$ to SWE is $\frac{\partial \Delta T_{B}}{\partial S W E}$ where the partial

215 derivatives indicate that $\Delta T_{B}$ is not only a function of SWE. If the brightness temperature difference 216 observation has a precision $\Delta\left(\Delta T_{B, o b s}\right)$ then the SWE at which saturation occurs is defined from:

$\left(\left.\frac{\partial \Delta T_{B}}{\partial S W E}\right|_{S W E}\right)^{-1} \Delta\left(\Delta T_{B, o b S}\right)>\Delta S W E_{a}$

Therefore the saturation value depends on the acceptable uncertainty in SWE, the precision of the observing system and the properties and uncertainties associated with the sensitivity of $\Delta T_{B}$ to changes in SWE. This result holds for ideal snow, and demonstrates the possibility that the saturation value is not globally fixed. For example, with an uncertainty of $2 \mathrm{~K}$ in observed brightness temperature difference and a SWE error threshold of $10 \mathrm{~mm}$ for the uniform snowpack in Figure 1, the saturation SWE rises to $195 \mathrm{~mm}$, equivalent to $108 \mathrm{~cm}$ depth. 
However, in real situations this is nontrivial to determine, as simulating the radiative transfer of actual snow profiles leads to additional uncertainty in $\Delta T_{B}(S W E)$ which must also be considered. Given an optimistic assessment of our ability to simulate radiative transfer in snow and observational uncertainties, this saturation threshold will be assumed to limit the utility of passive microwave measurements to snowpacks of $<180 \mathrm{~mm} \mathrm{SWE}$ or under 1 metre in depth.

Davenport et al. (2012) showed clearly that the functional form of $\Delta T_{B}(S W E)$ depends on the microstructural properties of the snow. The physical basis of $\Delta T_{B}$ 's sensitivity to microstructural properties can be explored by assuming that the snow is a collection of spheres in each other's far fields, for which the single scattering properties can be calculated from Mie theory (Mie, 1908). In particular, the single scattering albedo is actually a function of the size parameter $x=\frac{2 \pi r}{\lambda}$ where $r$ is the radius of the scatterer and $\lambda$ the wavelength. Single scattering properties for non-spherical grains have also been determined (Teschl et al. 2010), although radiative transfer models (RTMs) generally assume sphericity.

Critically, it is the ratio of scatterer size to wavelength which determines the single scattering parameters and so the retrieved signal is strongly affected by the size of the scatterer as well as the wavelength of the light. Figure 2 shows the brightness temperature differences assessed for snow with scatterer diameters ranging from $0.2 \mathrm{~mm}$ to $1.0 \mathrm{~mm}$ in $0.2 \mathrm{~mm}$ increments and Table 2 shows how the Chang sensitivity depends strongly on this value. Grains of $0.2 \mathrm{~mm}$ diameter are typical of fresh snowfall, and $1.0 \mathrm{~mm}$ of moderate sized depth hoar at the bottom of snow layers, although larger and smaller sizes do occur. From Figure 2 and Table 2 it can be seen that the saturation value of the signal will also depend on the properties of the snow.

The Mie approach provides useful physical insight about scattering of radiation in snow but any observations of the structure of real snowpacks show that snow is a complex, porous medium and as such these microstructural parameters are accounted for in a number of ways, such as specific surface area (SSA), optical grain size and correlation length. The optical grain size approximation comes from modelling the snow as a collection of spheres in each other's far fields, with the optical grain size defined as the spherical grain size required to reproduce the optical properties of the real snow. This size can vary with wavelength (Liu, 2004) and with grain shape (Macke et al. 1996).

Grenfell \& Warren (1999) found that if the optical properties of nonspherical snow were modelled using spheres, then spheres with the same SSA best matched the optical properties of the snow, for which the diameter can be determined from other properties using;

$D_{q}=\frac{6 M}{\rho S}$ 
Where $M$ is the total snow mass in a selected volume, $\rho$ the snow density and $\mathrm{S}$ the total ice-air interface area.

258

259

260

261

262

Correlation length is defined as the gradient of the spatial autocorrelation at a displacement of zero, and like specific surface area is defined independently of grain shape. It can be calculated from mean intercept lengths (Smith \& Guttman, 1953), by numerical analysis of the autocorrelation gradient, or by fitting to an assumed exponential autocorrelation function. There are also functions for converting from correlation length to optical grain size (e.g. Mätzler 2000; Wiesmann et al 2000; Mätzler 2002).

\section{Assimilation of passive microwaves to improve snow mass estimation}

\subsection{Assimilation of passive microwave brightness temperatures}

Microwave-only algorithms retain large uncertainties due to issues with forest coverage and changes in the scattering properties of snow, driven primarily by the snow's microstructure. However, if these effects could be quantified then an assimilation scheme would be able to extract information from the retrieved brightness temperatures to improve a snow analysis.

Sun et al. (2004) suggested a scheme which forecasts the snow cover using a LSM before assimilating SWE estimated from PM. They performed an experiment using a synthetic truth generated by the LSM versus two alternative model runs with strongly perturbed initial conditions, one of which assimilated observations from the truth using a Kalman Filter, and one which was left to run as an open loop. They demonstrated that the assimilation scheme returned the analysis state close to the truth within 1 week, and then a later study by Dong et al. (2007) simulated SWE in North America with and without the assimilation of the SMMR SWE product. Assimilation of the SMMR product improved the analysis where SWE $<100 \mathrm{~mm}$, provided the SMMR product was quality controlled.

However, this approach did not account for the changes in snow microstructure which affect the scattering, as the SMMR-based SWE product is based on a variant of the Chang Algorithm. A more comprehensive approach is detailed in Durand and Margulis (2006), who describe an Ensemble Kalman Filter (EnKF) approach to assimilating microwave brightness temperatures.

The Kalman Filter approach consists of two steps to produce an analysis of the variables of interest, which will be some vector $\mathbf{x}^{\mathrm{a}}$ whose components represent snow properties such as the density and grain size of each snow layer. In the first step, the analysis $\mathbf{x}_{k-1}^{a}$ from the previous timestep $t=k-1$ is propagated using a model $M$ to produce a forecast $\mathbf{x}_{\mathrm{k}}^{\mathrm{f}}$ :

$\mathbf{x}^{\mathrm{f}}\left(t_{k}\right)=M_{k-1}\left[\mathbf{x}^{\mathrm{a}}\left(\mathrm{t}_{\mathrm{k}-1}\right)\right]$ 
This forecast is then updated with reference to observations:

288

289

290

291

292

293

294

295

296

297

298

299

300

301

302

303

304

305

306

307

308

309

310

311

312

313

314

315

$\mathbf{x}^{\mathrm{a}}\left(\mathrm{t}_{\mathrm{k}}\right)=\mathbf{x}^{\mathrm{f}}\left(t_{k}\right)+\mathbf{K}_{k}\left(\mathbf{y}_{k}-H_{k}\left[\mathbf{x}^{\mathrm{f}}\left(t_{k}\right)\right]\right)$

Where $\mathbf{y}_{k}$ is the observation vector and $H_{k}$ is an operator which converts the state vector into an equivalent observation. In the case of snow remote sensing, it is some model of snow's radiative transfer that converts the known snow properties from the state vector into a vector of observable brightness temperatures or some combination thereof. $\mathbf{K}_{k}$ is the Kalman Gain, which acts as the weighting function and depends on the error covariances of the forecast $\mathbf{P}^{\mathrm{f}}$ and the observations $\mathbf{R}_{\boldsymbol{k}}$ :

$\mathbf{K}_{k}=\mathbf{P}^{\mathrm{f}}\left(t_{k}\right) \mathbf{H}_{\mathrm{k}}^{T}\left[\mathbf{H}_{k} \mathbf{P}^{\mathrm{f}}\left(t_{k}\right) \mathbf{H}_{\mathrm{k}}^{T}+\mathbf{R}_{\mathrm{k}}\right]^{-1}$

Here $\mathbf{H}_{\mathrm{k}}$ is the linearised approximation of the observation function $H_{k}$. It can be seen that as observational error decreases, the Kalman gain increases and greater weight is placed on the observations. The forecast error covariance $\mathbf{P}^{\mathrm{f}}\left(t_{k}\right)$ consists of the model error covariance $\mathbf{Q}_{k-1}$ and the error covariance introduced due to errors in the previous step's analysis, $\mathbf{P}^{\mathrm{a}}\left(t_{k-1}\right)$ :

$\mathbf{P}^{\mathrm{f}}\left(t_{k}\right)=\mathbf{M}_{\mathrm{k}-1} \mathbf{P}^{\mathrm{a}}\left(t_{k-1}\right) \mathbf{M}_{\mathrm{k}-1}^{T}+\mathbf{Q}_{k-1}$

where $\mathbf{M}_{k-1}$ is the linearised approximation of the forecast operator $M$. Estimating this component of the error covariance can be enormously computationally expensive, leading to the attraction of the EnKF where a model ensemble allows the generation of statistics to approximate $\mathbf{M}_{\mathrm{k}-1} \mathbf{P}^{\mathrm{a}}\left(t_{k-1}\right) \mathbf{M}_{\mathrm{k}-1}^{T}$ and therefore allow the calculation of the Kalman Gain.

The Kalman Gain is also required to calculate the new analysis' error covariance $\mathbf{P}^{\mathrm{a}}\left(t_{k}\right)$, which is reduced by the assimilation of observations relative to the forecast:

$\mathbf{P}^{\mathrm{a}}\left(t_{k}\right)\left(\mathbf{I}-\mathbf{K}_{\mathrm{k}} \mathbf{H}_{\mathrm{k}}\right) \mathbf{P}^{\mathrm{f}}\left(t_{k}\right)$

Durand and Margulis (2006) tested this approach with a synthetic experiment of snowpack progression in the US. The system truth was taken to be a single model run with forcing perturbed by doubling the precipitation and adding autocorrelated noise to mimic known issues of gauge undercatch. Synthetic passive microwave observations at SSM/I or AMSR-E frequencies were simulated by the Microwave Emission Model of Layered Snowpacks (MEMLs, Wiesmann and Mätzler (1999)) corrupted with $2 \mathrm{~K}$ white noise, and synthetic albedo observations were taken from the truth run with $5 \%$ white noise applied.

Forecasts were generated by an ensemble of 100 LSM replicates with perturbations applied to forcing and model parameters which allowed the mean forecast state and the forecast error covariance to be 
determined from the ensemble statistics. Synthetic albedo observations were assimilated daily at $1 \mathrm{pm}$ and passive microwave observations at 1 am to mimic MODIS and AMSR-E overpass times.

The regular assimilation of SSM/I frequencies alone significantly reduced both bias and root mean square error (RMSE) of SWE by approximately $85 \%$ relative to the open-loop simulation. The EnKF approach also allowed an assessment of the contribution of each channel, which indicated that the majority of the SWE improvement occurred due to the assimilation of the $37 \mathrm{GHz}$ channel at both polarisations. The $89 \mathrm{GHz}$ channel appeared to marginally worsen the SWE analysis by nudging it away from truth, however it significantly improved the grain size analysis which was vital for the brightness temperature simulations.

Having demonstrated the assimilation approach using a synthetic experiment, the later work of Durand et al. (2008) used data from the University of Tokyo's Ground Based Microwave Radiometer (GMBR-7) and snowpits at NASA's Cold Land Processes Experiment (CLPX) to test the performance of the MEMLS radiative transfer model. Furthermore, they were able to identify accuracy criteria for the snow state variables. They determined that simulated optical grain size should be accurate within $\pm 0.045 \mathrm{~mm}$ and the density of melt-refreeze layers within $\pm 40 \mathrm{~kg} \mathrm{~m}^{-3}$ in order for predicted brightness temperature errors to be small enough that the assimilation procedure improves the analysis.

Further work has considered the effect of spatial scaling on the analysis, with different spatial resolutions in LSMs and microwaves explored in De Lannoy et al. (2010) while Andreadis et al. (2008) discusses how to account for snow's spatial variability in an assimilation scheme.

\subsection{GlobSnow}

\subsubsection{Methodology}

The European Space Agency (ESA) GlobSnow project's aim is 'production of global long term records of snow parameters intended for climate research purposes on hemispherical scale.' (Finnish Meteorological Institute, 2012). The Globsnow SWE product is a system where the prior state is estimated from field observations of snow depth, with updates related to the satellite observed brightness temperature difference $\left(\Delta T_{B, V}\right)$ at vertical polarisation between channels near $19 \mathrm{GHz}$ (T19V) and $37 \mathrm{GHz}(\mathrm{T} 37 \mathrm{~V})$.

The use of a brightness temperature difference reduces the sensitivity of the satellite observations to absolute temperatures; if non-snow surfaces are in the field of view and they have the same emissivity at both $19 \mathrm{GHz}$ and $37 \mathrm{GHz}$, then their effect on the measured brightness temperature difference is dependent only on the area they cover and is independent of their temperature.

Globsnow produces maps of SWE across the Northern Hemisphere on a $25 \mathrm{~km}$ Equal Area Scalable Earth (EASE) grid, with areas defined as too watery ( $>50 \%$ open water) or too mountainous (standard 

deviation of elevation >200 m) masked out. Largely based on the approach of Pulliainen (2006), its methodology is explained in detail in Takala et al. (2011) and proceeds as follows:

1) The forecast snow depth map is generated by ordinary kriging between in-situ snow depth observations provided by the ECMWF and SCCONE (Snow Cover Changes Over Northern Eurasia, Kitaev et al. 2002), and the in-situ measurements are given an assumed variance of $150 \mathrm{~mm}^{2}$ based on comparison with coincident snow surveys. This forecast map at time $t$ contains the a priori snow depth $\widehat{D}_{r e f, t}$ and its variance $\sigma_{D, r e f, t}^{2}$.

2) At each grid point where a snow depth observation exists, the Helsinki University of Technology radiative transfer model is used to simulate the brightness temperature difference $\Delta T_{B}=\mathrm{T} 19 \mathrm{~V}-\mathrm{T} 37 \mathrm{~V}$. The effect of vegetation is included in the radiative transfer, dependent on forest cover fraction in Eurasia, or at $80 \mathrm{~kg} \mathrm{~m}^{-3} \mathrm{ha}^{-1}$ stem volume in North America. A single snow layer of $0.24 \mathrm{~g} \mathrm{~cm}^{-3}$ density is assumed and snow depth is taken from the in-situ observation. Grain size is varied at each location $i$ with the result obtained according to the cost function:

$\min _{d_{0, i}}\left\{\left[\left(T 19 V_{\text {mod }}\left(d_{0, i}, D_{\text {ref }, i}\right)-T 37 V_{\text {mod }}\left(d_{0, i}, D_{\text {ref }, i}\right)\right)-\left(T 19 V_{\text {obs }}-T 37 V_{\text {obs }}\right)\right]^{2}\right\}$

where $d_{0, i}$ is the grain size at the $i^{\text {th }}$ location, which is allowed to vary and $\mathrm{D}_{\mathrm{ref}, \mathrm{i}}$ is the locally measured snow depth. The final grain size $\left(\mathrm{d}_{0}\right)$ and its error variance $\left(\sigma_{d 0, t}^{2}\right)$ at each measurement location come from the ensemble of the nearest stations $(\mathrm{N}=6)$.

3) A full grain size map with variances is generated by kriging between the point grain size estimates from step 2).

4) At each grid cell, the grain size value and an assumed constant density of $0.24 \mathrm{~g} \mathrm{~cm}^{-3}$ is used as input to the HUT radiative transfer model by varying the snow depth $D_{t}$ to obtain:

$\min _{D_{t}}\left\{\left(\frac{\left(T 19 V_{\text {mod }}\left(D_{t}\right)-T 37 V_{\text {mod }}\left(D_{t}\right)\right)-\left(T 19 V_{o b s}-T 37 V_{o b s}\right)}{\sigma_{t}}\right)^{2}+\left(\frac{D_{t}-\widehat{D}_{r e f, t}}{\sigma_{D, r e f, t}}\right)^{2}\right\}$

where the variance at time $t, \sigma_{t}^{2}$ is obtained from a Taylor expansion of $\mathrm{T}_{\mathrm{B}}\left(D_{t}, d_{0, t}\right)$ with respect to grain size, which leads to:

$\sigma_{t}^{2}=\left(\frac{\partial T_{B}\left(D_{t}, d_{0, t}\right)}{\partial d_{0}}\right)^{2} \sigma_{d_{0}, t}^{2}$

This variance provides the weighting of the microwave contribution, allowing a large correction to the forecast when the SWE sensitivity is high but introducing a large cost to microwave based adjustments when the signal is saturated with respect to SWE but $\partial T_{B} / \partial d_{0}$ grows. This effect is seen in Figure 2 as the increasing spread in simulated $\Delta T_{B}$ for different grain sizes. 


\subsubsection{Limitations of GlobSnow}

Globsnow was validated with independent in-situ snow depth measurements from campaigns in the Former Soviet Union, Finland and Canada. RMSE values of $<40 \mathrm{~mm}$ were found where SWE was below $150 \mathrm{~mm}$, although errors increase for thicker snow. Assimilating the passive microwave data was found to improve on the forecast, thus demonstrating the utility of microwave retrievals.

Hancock et al. 2013 considered Globsnow and the Chang-based AMSR-E and SSM/I-only SWE products for the purpose of assessing LSMs. The Chang-based products were found to spike towards the end of the season, which was attributed to melt-refreeze cycles forming ice lenses which increase the effective grain size and cannot be accounted for in the Chang-based approach which assumes a static snow microstructure.

However, a number of questionable assumptions remain in the Globsnow approach. The assumption of constant density is not necessarily valid, as snow settles and increases in density during the season due to metamorphism and overburden (Anderson 1976), and variations in density or in the effect of vegetation are included through varying the grain size parameter which is an unphysical approach. Furthermore, the snow depth forecast is produced purely from interpolated observations, which as previously noted are biased towards low latitudes, low altitudes and clearings in forests. These biases could be accounted for by a LSM, which in addition to producing a snow depth forecast could also produce a forecast of the density and grain size.

Durand et al. (2009) showed that even a relatively simple land surface model coupled to a microwave emission model improved snow depth estimates once microwave brightness temperatures were assimilated. The later work of Brucker et al. (2011) and Toure et al. (2011) coupled the snow model Crocus (Brun et al., 1992) to the MEMLS radiative transfer model and found that point observations of microwave brightness temperatures at both H-pol and V-pol were generally well simulated.

Brucker et al. (2011) noted that late season grain growth was not well modelled in Crocus, and Toure et al. (2011) indicated that ice lenses must be accounted for. On a larger geographical scale, Dechant \& Moradkhani (2011) reported that assimilating brightness temperatures with the SNOW-17 snow model and a soil moisture model showed potential benefit for operational stream flow forecasting.

Naturally, increasing physical complexity leads to increased computational expense and computational expense is also affected by the number of layers in the snow model. Most land surface models typically limit the number of snow layers, with the ECMWF's Tiled ECMWF Scheme for Surface Exchange over Land (TESSEL) limited to one layer (Dutra, et al., 2010) whereas the Joint UK Land Environment Simulator (JULES) can run up to a user-defined number of layers, with new layers only introduced beyond certain thickness thresholds (Best, et al., 2011). 
411 In reality snowpacks almost always have distinct physical layers and this stratigraphic contrast can

412 have important effects on the radiative transfer. Lemmetyinen et al. (2010) compared passive

413 microwave measurements taken in-situ with layered snow information and found that the simulated

414 brightness temperature was affected by whether or not snow layering was included. These approaches

415 used field-observed layer properties, but did not consider how the radiative transfer model would

416 perform if provided with profile information as it would be output by a model.

417 This is assessed here through the experiments detailed in Section 4, where measured snow profiles

418 from CLPX snowpits are resampled to differing layering structures. After a scene simulation

419 experiment to confirm that the HUT radiative transfer model is able to reproduce observations within

420 acceptable uncertainties, the simulated $\Delta T_{B, V}$ values for each snowpit when resampled to different

421 layering structures are compared. This comparison across a large number of snowpits allows

422 estimation of the bias and variance introduced when the layering structure is simplified.

4. Methods

4.1 The Cold Land Processes Experiment (CLPX) Resampled Snowpits The CLPX dataset (detailed in Cline, et al., 2002) provides snow profiles from a large number of snowpits over four Intensive Observation Periods (IOPs). Two of these periods, IOP3 and IOP4 coincide with measurements of microwave brightness temperature from both SSM/I and AMSR-E and as such these periods are assessed here. Snowpit profiles provided snow properties for HUT radiative transfer simulations, which were compared with the satellite retrievals to confirm HUT's applicability.

Figure 3 shows the CLPX study area, largely in Colorado, US and the snowpits were within the three Mesoscale Study Areas (MSAs) each of which is approximately $25 \mathrm{~km}$ by $25 \mathrm{~km}$, the size to which AMSR-E and SSM/I 19V and 37V brightness temperatures are resampled.

434 For the first $\Delta T_{B, V}$ simulations, snow profiles were produced with layers of $10 \mathrm{~cm}$ thickness, limited

435 by the spatial resolution of the temperature and density measurements. These profiles are referred to 436 here as the N-layer case and are assumed to represent truth. In reality, snow layers are of irregular 437 depth, but LSMs often feature prescribed layer depths and the aim of this experiment is to compare 438 LSM-like outputs.

439 Density and temperature were drawn directly from the field measurements, while the mean of the 440 minimum and maximum extent of the average common grain was taken as the grain size, following 441 Davenport et al. (2012). Grain sizes were reported by the observers by stratigraphic layer, rather than 442 at $10 \mathrm{~cm}$ intervals, and these were mass weighted onto the $10 \mathrm{~cm}$ profile. 
443 As LSMs commonly feature a thin top layer to improve numerical handling of the surface energy

444 exchange, snowpits were resampled from the CLPX observational data with and without a $2 \mathrm{~cm}$

445 surface layer. This did not affect any of the key results, and so arbitrarily the case with a $2 \mathrm{~cm}$ surface

446 layer is presented.

447 The snowpits were then resampled to profiles of 1 to 5 equally sized layers subject to a minimum

448 layer size of $10 \mathrm{~cm}$, with the mass-weighted grain size, temperature and density from the relevant

449 observational layers applied to each of the resampled layers. Figure 4 illustrates sample layering

450 profiles, where the $2 \mathrm{~cm}$ top layer is excluded from the layer count and for a snowpit of depth $d$ each

451 of the $n$ main layers is of depth $(d-2) / n \mathrm{~cm}$. The minimum layer size criterion meant that, for

452 example, a snowpit of $12 \mathrm{~cm}$ depth would be identical in all layer cases and consist of a single $10 \mathrm{~cm}$

453 layer and the top $2 \mathrm{~cm}$ layer, even in the 5- or $\mathrm{N}$ - layer cases.

454 This approach attempts to mimic a depth structure that might be output by an LSM. A key feature is

455 the prescribed layer thicknesses, as each layer depth can be determined uniquely from the total snow

456 depth, thus removing the need for layer thickness components in the snow state vector. However, it is

457 not necessarily representative of an individual LSM snow scheme, as a variety exist and rather than

458 select some arbitrary combination of layer sizes for each of the 1- to 5-layer schemes a more

459 simplistic approach was adopted.

460 Ground surface temperature was taken to be the temperature measured at $0 \mathrm{~cm}$ height. Missing data

461 were linearly interpolated or, if they were at the top or bottom of the pack then the nearest

462 neighbouring value was used. If too many data were missing for this interpolation, then the pit was

463 removed from the analysis.

\subsection{Comparison: Layered HUT Scene Simulation versus Observations}

465 The HUT performance was first assessed by simulating the scene brightness temperatures based on 466 the snowpit information, and comparing these simulations with satellite retrievals. The multi-layer 467 implementation of the HUT model (Lemmetyinen et al., 2010) simulated the brightness temperatures 468 at $18.7 \mathrm{GHz}$ and $36.5 \mathrm{GHz}$ vertical polarisation for each snowpit with each of the layering structures 469 described in Section 4.1. The brightness temperature difference,

471 was considered throughout, for consistency with the Globsnow product. This offers the further

472 advantage of being less sensitive to errors in ground or exposed-vegetation temperatures.

473 In addition to the HUT simulations, a Chang-algorithm output based on Equation (1) and using the

474 CLPX coefficients reported in Section 2.3 was produced for each snowpit. 
475 In each of the CLPX Mesoscale Study Areas (MSAs), the snowpits were assumed to be representative 476 of the actual snowpack, such that the mean $\Delta T_{B, V}$ of all of the snowpits within the MSA represents the $477 \Delta T_{B, V}$ contribution of the snow within that MSA. The scene brightness temperature has contributions 478 from snow, open ground and vegetation over snow.

where $A$ is the fractional area of the pixel that is either open or snow covered and FF is the forest fraction. With the assumption that $\Delta T_{B, o p e n}=0$, the equation becomes:

$\Delta T_{B, V, \text { scene }}=(1-F F) A_{\text {snow }} \Delta T_{B, \text { snow }}$

Since the distribution of the snowpit properties is assumed to match the distribution of the snow within the scene, then the brightness temperature difference of the snow should be equivalent to the average brightness temperature difference of the $N$ snowpits.

$\Delta T_{B, V, \text { scene }}=(1-F F) \frac{A_{\text {snow }}}{N} \sum_{i}^{N} \Delta T_{B, V, i}$

where $\Delta T_{B, V, i}$ is the brightness temperature difference between $18.7 \mathrm{GHz}$ and $36.5 \mathrm{GHz}$ at vertical polarisation for the $i^{\text {th }}$ snowpit.

Snow properties were assumed to be static throughout an IOP such that all measurements within each IOP could be used in the same analysis.

The fractional area of snow for each IOP and for each MSA was estimated by using the 8-day maximum extent snow cover map from MODIS (Haran, 2003), taken as the fraction of snow covered area divided by the total non-cloud covered area. This offers the advantage of minimising the effect of cloud cover, although can provide inconsistent results if significant snowfall or melt occurs during the 8 days. The MODIS product is at $500 \mathrm{~m}$ spatial resolution, so features 2,500 pixels within each $25 \mathrm{~km}$ passive microwave grid point.

Forest cover was estimated for each MSA using QuickSCAT data available from Nilsson (2003) and the forest correction factor applied individually for each MSA. More complex forest correction approaches exist (e.g. as shown in Foster, et al., 2005), but are not adopted here.

Six sets of simulated scene $\Delta T_{B, V}$ values were produced, for each of the layering structures (1- to 5layer plus the N-layer truth) and these were compared with SSM/I and AMSR-E values, where all measurements within a day of each IOP period were recorded. It should be noted that for IOP4, many snowpacks reported temperatures around the melt point, suggesting the presence of liquid water, which acts to reduce the brightness temperature difference through greater absorption and emission at 
both wavelengths (Hallikainen, 1989). However, the percentage of snowpits that were noted by fieldworkers as 'wet' in the metadata did not exceed $3 \%$ in either period.

\subsection{Comparison: N-layer versus Fewer Layers of Stratigraphic Information}

Using the same resampled snowpit data to represent realistic profiles as might be output by an LSM, the $\Delta T_{B, V}$ values simulated by the 1 - to 5 - layer simulations were assessed relative to the $\mathrm{N}$-layer simulations, which were assumed to be truth.

Uncertainty introduced into the $\Delta T_{B, V}$ by simplification of the model layering was determined from the difference between outputs for each of the 1- to 5-layer models versus the N-layer model. Bias and standard deviation of these residuals is reported in Section 5.3 for each of the simpler models as a function of the model layer thickness.

\section{Results and Analysis}

\subsection{Snow Properties at CLPX Sites}

Table 3 summarises the main snow properties recorded from the snowpits and MODIS data, including the number of relevant snowpits once those with insufficient data were deleted. Notably, the snow in IOP4 during March was thicker than during IOP3 in February, although the snow cover fraction had declined from universal coverage to around $80 \%$.

It should be noted that the average depth and SWE is not necessarily a good representation, as the distribution of snowpit values is not symmetric, with a bias towards thin pits in IOP3 and a bimodal distribution in IOP4, with a number of pits showing thin snow $(<50 \mathrm{~cm})$ and a number showing thicker snow $(\sim 200 \mathrm{~cm})$. The overall distribution is shown in Figure 5 although thicker snow predominated at Rabbit Ears and Fraser, and thinner snow at North Park. Additionally, IOP3 saw generally cooler snow (-3.6 C versus $-2.2 \mathrm{C})$ and marginally smaller average grain sizes $(0.57 \mathrm{~mm}$ versus $0.60 \mathrm{~mm}$ ).

\subsection{Simulated Scene Brightness Temperatures}

Figure 6 shows the simulated scene $\Delta T_{B, V}$ from Equation (15), using the N-layer and 1-layer HUT model compared with AMSR-E and SSM/I retrievals. Here the scene is represented by the average of all 3 MSAs. The difference between the N-layer and 1-layer simulations is minimal (0.01 K in IOP3, $0.40 \mathrm{~K}$ in IOP4) compared with the difference between simulations and observations, of approximately $3 \mathrm{~K}$ in IOP3 and $2 \mathrm{~K}$ in IOP4.

Table 4 shows the brightness temperature difference simulated using different model layering profiles versus the observations. There is a negligible difference in the mean simulated by different layering 
536 profiles. The overall Chang estimates are close to observations at IOP3, but are too high during IOP4.

537 The Chang algorithm's poorer performance at individual MSAs (RMSE $=17 \mathrm{~K}$ ) versus HUT (RMSE

$538=8 \mathrm{~K}$ ) is hidden by the averaging over the 3 MSAs. During IOP3 use of the Chang algorithm results

539 in a large $\Delta T_{B, V}$ overestimate at Rabbit Ears MSA, which is counteracted by a large underestimate at

540 North Park MSA. During IOP4, a very large (32 K) overestimate by the Chang algorithm due to

541 saturation in the deep snowpits is partially offset by a $13 \mathrm{~K}$ underestimate at North Park.

542 The largest contributor to the HUT RMSE was due to a large underestimate during IOP4 at North

543 Park, where simulated $\Delta T_{B, V}$ were of order $1 \mathrm{~K}$ versus observed values of $14 \mathrm{~K}$. This is consistent

544 with the results of Davenport et al. (2012) for IOP4 and suggest that the average snowpack was

545 deeper than that sampled by the snowpits. The majority of North Park snowpits occurred near roads

546 and might therefore be biased toward thinner snow and excluding IOP4 North Park results, the HUT

547 RMSE drops from $8 \mathrm{~K}$ to $6 \mathrm{~K}$, while Chang increases from $17 \mathrm{~K}$ to $18 \mathrm{~K}$. The increase in Chang error

548 is due to its North Park error being an underestimate and therefore limited in size to below the $14 \mathrm{~K}$

549 observation.

550 A number of assumptions contribute to the uncertainty in the $\Delta T_{B, V}$ estimates: static snow properties,

551 dry snowpits, a simplified vegetation model and unbiased sampling of the real snow by the snowpits.

552 Furthermore, other work (Picard et al. 2009) has found that effective microwave grainsize does not

553 necessarily match that estimated by field observations. In light of these assumptions, the HUT

554 simulations are largely consistent with the satellite observations and therefore justify continued

555 assessment using this model.

556 The small differences in scene simulated $\Delta T_{B, V}$ values when using the N-layer or 1-layer HUT

557 realisations does not necessarily indicate that they are equally valid, as the averaging over a large

558 number of simulations will suppress the variance. In the Globsnow assimilation scheme a single snow

559 profile is taken to represent the snow at each grid point, rather than the average of 59 profiles used

560 here, and for a single simulation, the output $\Delta T_{B, V}$ depends on the layering structure provided to the

561 profile.

562

\subsection{Differences Due to Layering Detail}

563 It appears that for the CLPX pits, using the HUT radiative transfer model to generate the scene

564 brightness temperature difference improves the simulation relative to using the Chang algorithm 565 approach. Furthermore, Lemmetyinen et al. (2010) reported that RMSE and bias were reduced at 566 these microwave channels when HUT accounted for the multiple layering of snow, rather than using 567 bulk averages in a single layer. 
It was therefore assumed that the best simulation of $\Delta T_{B, V}$ was provided by the HUT model run with the N-layer realisation of the CLPX snowpit properties, and the performance of simplified layer models should be compared to this. Here the same brightness temperature simulations as in Section 5.2 were used, based on the CLPX snowpits as these represent realistic snow profiles.

Simulated $\Delta T_{B, V}$ was compared on a pit-by-pit basis, where the simulation for the Chang algorithm and the 1- to 5- layer realisations of HUT were compared to the N-layer output. Figure 7 demonstrates the comparison for the Chang algorithm and the 1- and 5-layer HUT output.

For these snow properties the Chang estimate shows a low bias in simulated $\Delta T_{B}$ across much of the range, but a very large positive bias at high values of SWE. This is due to the CLPX snow properties differing from those assumed by Chang for the low values of SWE, and by saturation of the signal at higher SWE values.

For the HUT simulations, bias is much smaller and scatter is reduced relative to the Chang estimate. This scatter is an estimate of the uncertainty introduced by simplifying the model to fewer layers. At the lowest brightness temperature differences, the scatter is zero as the minimum layer depth criterion ensures that for pits of depth $<12 \mathrm{~cm}$, the 1-layer and N-layer realisations are identical. The scatter is less prominent for IOP3 than for IOP4, possibly due to IOP4 featuring a larger number of thicker snowpacks with potentially more complex stratigraphy.

In an assimilation system, the snow model may output a single profile for each grid point, equivalent to a single point on the graphs in Figure 7, and the deviation about the 1:1 line indicates that use of a simplified profile will lead to different simulated $\Delta T_{B, V}$ values relative to the best simulation provided by the N-layer realisation.

To quantify this deviation, the residuals from the 1:1 fit were considered, i.e. the values

$\Delta T_{b, i}-\Delta T_{B, N}=\Delta T_{B, V_{\text {ilayers }}}-\left(\Delta T_{B, V}\right)_{\text {Nlayers }}$

where $\Delta T_{b, i}$ is the brightness temperature difference simulated with $i$ layers, $i$ is an integer from one to five and $\Delta T_{b, N}$ is the brightness temperature difference when a maximum of $N$ layers are included in the model profile. As throughout, $\Delta T_{B, V}$ represents the brightness temperature difference described in Equation (1).

The bias and standard deviation varies with snow thickness, and as such the residual in Equation (16) was returned as a function of layer thickness in the $1, \ldots, 5$ layer models and the results are shown in Figure 8, where only snow pits of depths up to $100 \mathrm{~cm}$ are considered. Beyond this value, signal saturation would reduce the weighting applied to the microwave observational increment in an assimilation scheme, justifying the neglect of thicker pits. 
It is apparent that as layer thickness is increased, the average deviation from the $\mathrm{N}$-layer simulation

601 (which contains layers of $10 \mathrm{~cm}$ thickness) increases, and there is also an increase in bias, most likely

602 due to layer boundary effects.

603 As the Globsnow approach is allowed to freely scale grain size at the snow depth observation

604 locations, it is plausible that it accounts for this bias by artificially increasing the grain size depending

605 on snow thickness. Changing the effective grain size is already known to account for variation in

606 vegetation outside the model assumptions.

607 This would have a secondary level effect on the Globsnow assimilation scheme, by changing the 608 variance of estimated grain size $\sigma_{d_{0}, t}$ in Equation (11) if the ensemble of stations used for the 609 averaging have different snow depths (and therefore different grain size biases).

610 The main concern for the assimilation scheme, however, is the random variance that is introduced, as

611 this means that the simulated $\Delta T_{B, V, \text { mod }}$ in the assimilation cost minimisation function (Equation (10))

612 should have additional variance associated with the neglect of snow stratigraphy. This variance is not

613 accounted for in Equation (11) which defines the weight given to the observational increment based

614 on the estimated variance. Instead, it is calculated from the single-layer model's brightness

615 temperature sensitivity to grain size, and the statistics of the ensemble of nearest station grain sizes.

616 It was suggested in Section 3.2.2 that future implementations of Globsnow might be improved by

617 using a LSM to provide grain size estimates in every grid cell, thus accounting for regional changes in

618 geography and meteorology that are beyond the Globsnow kriging approach, and for the well noted

619 bias in observation location towards low latitudes, altitudes and canopy cover.

620 Even if an LSM were to provide the snow state forecasts, the current weighting scheme would not

621 account for the variance introduced by its simplified layering relative to the truth. The LSM could be

622 allowed to increase in complexity and contain more layers, but computational expense would rise both

623 in the forecast step and in solving the update equation as the snow state vector and relevant covariance

624 matrices would grow to contain more layer properties.

625 A user could apply the approach adopted here to estimate the extra variance introduced to their

626 simulations as a function of the snow depth and their layering structure. Taking the gradient of the

627 standard deviation graph in Figure 9, the increase in error due to thickening of snow layers beyond 10

$628 \mathrm{~cm}$ was found to be $0.053 \pm 0.006 \mathrm{~K} \mathrm{~cm}^{-1}$. The total error from loss of stratigraphic information can

629 therefore be estimated from the snow depth and number of layers and is presented as a function of

630 SWE (calculated by applying the CLPX average density for snowpits $<100 \mathrm{~cm}$ depth) in Figure 10

631 for snowpits whose stratigraphy is averaged to 1, 2 or 3 layers.. 
Additionally, the estimated error in $\Delta T_{B, V}$ can be interpreted as an estimate of the $S W E$ error for this regime where the roughly linear relationship between $\Delta T_{B}$ and SWE holds, similarly to Equation (1) but for vertically rather than horizontally polarised microwaves. $\Delta S W E / \Delta\left(\Delta \mathrm{T}_{\mathrm{B}, \mathrm{V}}\right)$ was calculated from linear regression of the known SWE and N-layer calculated $\Delta T_{B, V}$ values for the pits of depth $<100 \mathrm{~cm}$, and found to be $2.45 \pm 0.09 \mathrm{~mm}_{\mathrm{SWE}} \mathrm{K}^{-1}$, and so error in $\Delta T_{B, V}, \Delta\left(\Delta T_{B, V}\right)$ was converted into an approximate SWE error using:

$$
\Delta S W E=\frac{\Delta S W E}{\Delta\left(\Delta T_{B, V}\right)} \Delta\left(\Delta T_{B, V}\right)
$$

For a CLPX snow profile of $100 \mathrm{~cm}$ depth (170 mm SWE), simplification of the stratigraphy from the measurement resolution of $10 \mathrm{~cm}$ down to a single layer of average properties leads to $\Delta T_{B, V}$ simulations that contain a $4.8 \mathrm{~K}$ error related to the loss of stratigraphic information, equivalent to 13 $\mathrm{mm} \mathrm{SWE}$ (7\% of total). In a 2-layer model, this error would be reduced to $2.1 \mathrm{~K}$ (5.6 mm SWE, 3\% of total) and for a 3-layer model $1.2 \mathrm{~K}$ (3.3 mm SWE, $2 \%$ of total).

The individual user must decide model detail based on the trade-off between precision and computational expense, and it is hoped that this approach will inform such decisions. A user might determine a given threshold for fractional or absolute error in SWE, and from this information could determine the number of layers to use in their model based on the snow depth.

\section{Discussion and Conclusions}

Snow is extremely important in terms of meteorology, climatology and hydrology. Its surface properties can affect atmospheric chemistry and the energy balance, and an abundance of remote sensing products with well characterised errors assess a wide variety of these surface properties, from grain size to contaminants to surface melt.

Snow Water Equivalent is of great interest and estimates of SWE are most easily defined as a remote sensing, model, reanalysis or station-based product. Each of these approaches provides its own advantages, but each also has drawbacks: reanalyses and station-based products suffer from sparse observations, models have uncertainties due to limitations in the physical modelling of complex processes in snow, and remote sensing products are global, but limited by signal saturation and do not provide a unique SWE solution on inversion due to their high sensitivity to other snow properties.

Data assimilation techniques that use microwave information to update a forecast from other sources have been suggested to improve snow mass estimation. ESA's GlobSnow uses modern assimilation techniques to bring together ground observations and remote sensing products, and has shown that assimilating microwave measurements does improve SWE estimates. GlobSnow isolates and accounts for the snow microstructure's contribution through a grain size parameter which is obtained by fitting 
ground measurements to satellite retrievals while assuming a single homogeneous snow layer. The

665 brightness temperature observable chosen by Globsnow is the difference between brightness temperatures at $19 \mathrm{GHz}$ and $37 \mathrm{GHz}$ vertically polarised microwaves, $\Delta T_{B, V}$.

667 The GlobSnow grain size estimate is reliant on point measurements of snow, which may vary greatly over relatively small areas (e.g. Hall, et al., 1991; Derksen, et al., 2009), and it is suggested that physically based snow models could provide an alternate source of information to improve the inversion of the passive microwave signal.

671 Snow forms in layers and its stratigraphy can be complex, though physical models are capable of reproducing this layering. Lemmetyinen et al. (2010) and Durand et al. (2011) showed that for simulation of brightness temperatures over small areas of snow, this complexity can be an important contribution to the signal. Globsnow ignores this complexity in determining the error covariance for weighting the observational increment in the update step, and this might lead to suboptimal updates.

The HUT radiative transfer model used in Globsnow was able to simulate satellite-observed $\Delta T_{B, V}$ with an RMSE of $8 \mathrm{~K}$, down from the $17 \mathrm{~K}$ RMSE associated with estimates made using the Chang algorithm typical of stand-alone microwave SWE products. The HUT RMSE was $6 \mathrm{~K}$ excluding one site where it was believed that snowpits were biased towards thin snow.

After confirming that the HUT radiative transfer model used in Globsnow was able to simulate satellite-observed scene brightness temperatures at NASA's CLPX, the HUT-simulated $\Delta T_{B, V}$ values for CLPX snowpits resampled to different layering structures were compared. Simulated $\Delta T_{B, V}$ for snow with the maximum possible level of stratigraphic detail based on the $10 \mathrm{~cm}$ resolution of CLPX density and temperature measurements was taken as truth, and deviations from this were treated as due to errors introduced by simplification of the stratigraphy to fewer layers.

686 Removing layering detail leads to a bias in the simulated $\Delta T_{B, V}$, likely due to the removal of reflection 687 effects at layer boundaries and possibly due to nonlinearities in the $\Delta T_{B, V}$ response to snow grainsize 688 and density. Globsnow can freely vary the grain size to account for this, but this is likely to have 689 second-order effects on the assimilation scheme.

690 Simulated $\Delta T_{B, V}$ values for the same snowpit at different levels of layering detail were found to vary, 691 with the standard deviation increasing approximately linearly with snow depth. For snow of depth 100 $\mathrm{cm}$ (172 $\mathrm{mm}$ SWE at the CLPX sites), the standard deviation in simulated $\Delta T_{B, V}$ values for a singlelayer model versus the $\mathrm{N}$-layer model was estimated at $4.8 \mathrm{~K}$, equivalent to approximately $13 \mathrm{~mm}$ SWE (7\% of total). Using 2 snow layers reduced the $\Delta T_{B, V}$ error to $2.1 \mathrm{~K}$ (5.6 mm SWE, $3 \%$ of total). 
Globsnow reports RMSE values of $40 \mathrm{~mm}$ for SWE < $150 \mathrm{~mm}$ using a single layer version of HUT, and the values found here suggest that layering could be a notable component of that RMSE.

A number of groups are working on coupling physical snow models with microwave emission models to improve estimates of SWE, and these error assessments are important to help users decide on model complexity, which carries a potentially high computational cost. This paper argues that this is a promising avenue for improving global estimates of SWE, but that not accounting for the effects of detailed stratigraphy can introduce unaccounted-for variance which degrades the performance of an assimilation scheme. The approach adopted here quantifies this variance for the HUT radiative transfer model, and presents it in such a way that it could be used to determine the snow layering structure in an LSM for use in an assimilation system.

Acknowledgments: MR is funded by National Environment Research Council studentship F3275903, and ID is a member of the National Centre for Earth Observation.

\section{References}

Anderson E (1976) A point energy and mass balance model of a snow cover, Silver Spring, MD:

Office of Hydrology, National Weather Service.

Andreadis K, Liang D, Tsang L, Lettenmaier D, \& Josberger E (2008). Characterization of Errors in a Coupled Snow Hydrology-Microwave Emission Model. J Hydrometeor , 9, 149-164.

Armstrong R, Brodzik M (2000). Validation of passive microwave snow algorithms. Proc IGARSS 2000. 4:1561-1563.

Armstrong R, Brodzik M, Knowles K, Savoie M (2005) Global monthly EASE-Grid snow water equivalent climatology. Boulder, Colorado USA: National Snow and Ice Data Center, URL http://nsidc.org/data/docs/daac/nsidc0271_ease_grid_swe_climatology.gd.html

Barnett TP, Adam J, \& Lettenmaier DP (2005). Potential impacts of a warming climate on water availability in snow-dominated regions. Nature, 438:303-309.

Best M, Pryor M, Clark D, Rooney G, Essery R, Ménard C, et al. (2011). The Joint UK Land Environment Simulator (JULES), model description - Part 1: Energy and water fluxes. Geosci Model Dev, 4:677-99. 
Betts A, Kohler M, Zhang Y (2009). Comparison of river basin hydrometeorology in ERA-Interim and ERA-40 reanalyses with observations. J Geophys Res, 114.

Brasnett B (1999). A global analysis of snow depth for numerical weather prediction. J Appl Meteorol, 38:726-740.

Brown RD, Mote PW (2009). The response of northern hemisphere snow cover to a changing climate. Journal of Climate, 22:2124-2145.

Brown R, Brasnett B, Robinson D (2003). Gridded North American monthly snow depth and snow water equivalent for GCM evaluation. Atmosphere-Ocean, 41(1):1-14.

Brucker L, Royer A, Picard G, Langlois A, Fily M (2011). Hourly simulations of the microwave brightness temperature of seasonal snow in Quebec, Canada, using a coupled snow evolutionemission model. Remote Sens of Environ, 115:1966-1977.

Brun E, David P, Sudul M, Brunot G (1992). A numerical model to simulate snow-cover stratigraphy for operational avalanche forecasting. Journal of Glaciology, 38(128):13-22.

Budyko M (1958). The Heat Balance of the Earth's Surface. Department of Commerce, Weather Bureau.

Carroll T, Cline D, Fall G, Nilsson A, Li L, Rost A (2001). NOHRSC operations and the simulation of snow cover properties for the coterminous U.S. $69^{\text {th }}$ Annual Meeting of the Western Snow Conference. Sun Valley, Idaho USA.

Chang A, Hall J, Foster D (1987). Nimbus7 SMMR derived global snow cover parameters. Ann Glaciol, 9(9):39-44.

Chang A, Kelly R, Josberger E, Armstrong R, Foster J, \& Mognard N (2005). Analysis of GroundMeasured and Passive-Microwave-Derived Snow Depth Variations in Midwinter across the Northern Great Plains. J Hydrometeor , 6, 20-33.

Clifford D (2010). Global estimates of snow water equivalent from passive microwave instruments: history, challenges and future developments. Int J of Remote Sens, 31(14):3707-3726.

Cline D, Elder K, Davis B, Hardy J, Liston GE, Imel D, et al. (2002). Overview of the NASA cold land processes field experiment (CLPX-2002). Hangzhou, China: SPIE Proceedings.

Davenport I, Sandells M, Gurney R (2012). The effects of variation in snow properties on passive microwave snow mass estimation. Remote Sens of Environ, 118:168-175. 
Dechant C, Moradkhani H (2011). Radiance data assimilation for operational snow and streamflow forecasting. Adv in Water Resour, 34(3):351-364.

Dee DP, Uppala SM, Simmons AJ, Berrisford P, Poli P, Kobayashi S, et al. (2011). The ERA-Interim reanalysis: configuration and performance of the data assimilation system. Q J of the Royal Meteorol Soc, 137:553-597.

De Lannoy G, Reichle R, Houster P, Arsenault K, Verhoest N, \& Pauwels V (2010). Satellite-Scale Snow Water Equivalent Assimilation into a High-Resolution. J Hydrometeor , 11, 352-369.

Derksen C, Sturm M, Listen G, Holmgren J, Huntington H, Silis A, et al. (2009). Northwest Territories and Nunavut snow characteristics from a subarctic traverse: implications for passive microwave remote sensing. J Hydrometeorol, 10:448-463.

Dominé F, Shepson P (2002). Air-Snow Interactions and Atmospheric Chemistry. Science, 297:15061510.

Dong J, Walker J, Houser P, \& Sun, C. (2007). Scanning multichannel microwave radiometer snow water equivalent assimilation. J Geophys Res, 112, D07108.

Drusch M, Vasiljevic D, Viterbo P (2004). ECMWF's global snow analysis: assessment and revision based on satellite observations. J Appl Meteorol, 43:1282-1294.

Durand M., \& Margulis S. (2006). Feasibility Test of Multifrequency Radiometric Data Assimilation to Estimate Snow Water Equivalent. J Hydrometeor , 7, 443-457.

Durand E, Kim E, \& Margulis S (2008). Quantifying Uncertainty in Modeling Snow Microwave Radiance for a Mountain Snowpack at the Point-Scale, Including Stratigraphic Effects. IEEE Trans on Geosci and Remote Sens , 46, 1753-1767.

Durand M, Kim E, Margulus S (2009). Radiance assimilation shows promise for snowpack characterization. Geophys Res Lett, 29(2).

Durand M, Kim E, Margulis S, Molotch N (2011). A first-order characterization of errors from neglecting stratigraphy in forward and inverse passive microwave modeling of snow. IEEE Geosci and Remote Sens Lett, 8:730-734.

Dutra E, Balsamo G, Viterbo P, Miranda P, Beljaars A, Schaer C, et al. (2010). An Improved Snow Scheme for the ECMWF Land Surface Model: Description and Offline Validation. J Hydrometeorol, 11:899-916. 
Dye D (2002). Variability and trends in the annual snow-cover cycle in Northern Hemisphere land areas, 1972-2000. Hydrol Proc, 16(15):3065-3077.

Dyer J, \& Mote T (2006). Spatial variability and trends in observed snow depth over North America. Geophys Res Lett, 33 (16).

Finnish Meteorological Institute. Globsnow project description (2012)

http://www.globsnow.info/snow_workshop_2012/presentations/GlobSnow_Fact_Sheet_EuropeanSate lliteSnowMonitoringActivities.pdf . Accessed 8th August, 2013.

Flanner M, Shell K, Barlage M, Perovich D, Tschudi M (2011). Radiative forcing and albedo feedback from the Northern Hemisphere cryosphere between 1979 and 2008. Nature Geosci, 4:151155.

Foster J, Sun C, Walker J, Kelly R, Chang A, Dong J, et al. (2005). Quantifying the uncertainty in passive microwave snow water equivalent observations. Remote Sens of Environ, 94:187-203.

Frappart F, Ramillien G, Biancamaria S, Mognard N, Cazenave, A (2006). Evolution of high-latitude snow mass derived from the GRACE gravimetry mission (2002-2004). Geophys Res Lett, 33.

Frei A, Miller J, Robinson D (2003). Improved simulations of snow extent in the second phase of the Atmospheric Model Intercomparison Project (AMIP-2). Geophys Res Lett: Atmospheres, 108.

Grenfell T, Warren S (1999). Representation of a nonspherical ice particle by a collection of independent spheres for scattering and absorption of radiation. J Geophys Res, 104(D24):3169731709.

Grippa M, Mognard N, Le Toan T (2005). Comparison between the interannual variability of snow parameters derived from SSM/I and the Ob river discharge. Remote Sens of Environ, 98:35-44.

Hall DK, Sturm M, Benson C, Chang AT, Foster JL, Garbeil H, et al. (1991). Passive microwave remote and in situ measurements of artic [sic] and subarctic snow covers in Alaska. Remote Sensing of Environment, 38(3):161-172.

Hall D, Riggs G (2007). Accuracy assessment of the MODIS snow products. Hydrol Proc, 21:15341547.

Hallikainen M (1989). Microwave radiometry of snow. Adv in Space Res, 9(1):267-275.

Hancock S, Baxter R, Evans J, Huntley B (2013). Evaluating global snow water equivalent products for testing land surface models. Remote Sens of Environ, 128:107-117. 
811 Haran T (2003). CLPX-Satellite: MODIS Radiances, Reflectances, Snow Cover and Related Grids.

812 MOD10A2. Boulder, Colorado USA: NSIDC: National Snow and Ice Data Center.

813 Khan V, Holko L (2009). Snow cover characteristics in the Aral Sea Basin from different data sources 814 and their relation with river runoff. J Marine Syst, 76:254-262.

815 Kitaev L, Kislov A, Krenke A, Razuzaev V, Martuganov R, Konstantinov I (2002). The snow cover 816 characteristics of northern Eurasia and their relationship to climatic parameters. Boreal Environ Res, $817 \quad 7: 437-445$.

818 Koskinen J, Pulliainen J, Hallikainen M (1997). The use of ERS-1 SAR data in snow melt monitoring. 819 IEEE Trans on Geosci and Remote Sens, 35:601-610.

820 Lemmetyinen J, Pulliainen J, Rees A, Kontu A, Qiu Y, Derksen C (2010). Multiple-layer adaption of 821 HUT snow emission model: comparison with experimental data. IEEE Trans on Geosci and Remote 822 Sens, 48:2781-2794.

823 Liu G (2004). Approximation of Single Scattering Properties of Ice and Snow Particles for High 824 Microwave Frequencies. J Atmospheric Sci, 61:2441-2456.

825 Macke A, Mueller J, Raschke E (1996). Single Scattering Properties of Atmospheric Ice Crystals. J of 826 the Atmospheric Sci, 53(19):2813-2825.

827 Mätzler C (2000). A simple snowpack/cloud reflectance and transmittance model from microwave to 828 ultraviolet: the ice-lamella pack. J Glaciol, 46(152):20-24.

829 Mätzler C (2002). Relation between grain-size and correlation length of snow. J Glaciol, 48:461-166.

830 Mie G (1908). Beiträge zur Optik trüber Medien, speziell kolloidaler Metallösungen. Annalen der 831 Physik, 3:377-445.

832 Nilsson A (2003). Qscat CLPX data. ftp://ftp.nohrsc.nws.gov/staff/nilsson/qscat/ accessed 15 April 8332013

834 Niu G-Y, et al. (2007). Retrieving snow mass from GRACE terrestrial water storage change with a 835 land surface model. Geophys Res Lett, 34.

836 Onogi, K., Tsutsui, J., Koide, H., Sakamoto, M., Kobayashi, S., Hatsushika, H., et al. (2007). The 837 JRA-25 Reanalysis. J of the Meteorol Soc of Jpn, 85(3):369-432.

838 Painter T, Bryant A, Skiles S (2012). Radiative forcing by light absorbing impurities in snow from 839 MODIS surface reflectance data. Geophys Res Lett, 39. 
841 brightness temperature in Antarctica. J Glaciol, 55(191):537-551.

842 Pulliainen J (2006). Mapping of snow water equivalent and snow depth in boreal and sub-arctic zones

843 by assimilating space-borne microwave radiometer data and ground-based observations. Remote Sens 844 of Environ, 101, 257-269.

845 Pulliainen J, Grandell J, Hallikainen M (1999). HUT Snow Emission Model and its Applicability to 846 Snow Water Equivalent Retrieval. IEEE Trans Geosci Rem Sens, 37(3):1378-1390.

847 Ramsay, B. (1998). The interactive multisensor snow and ice mapping system. Hydrol Process, $848 \quad 12: 1537-1546$.

849 Rawlins M, Fahnestock M, Frolkin S, Vörösmarty CJ (2007). On the evaluation of snow water 850 equivalent estimates over the terrestrial Arctic drainage basin. Hydrological Processes, 21(12):16168511623.

852 Rawlins M, Steele M, Holland M, Adam J, Cherry J, Francis J, et al. (2010). Analysis of the Arctic system for freshwater cycle intensification: observations and expectations. J Clim, 23:5715-5737.

854 Rienecker M, Suarez M, Gelaro R, Todling R, Bacmeister J, Liu E, et al. (2010). MERRA: NASA's modern-era retrospectiev analysis for research and applications. J Clim, 24:3624-3648.

856 Rittger K, Painter T, Dozier J (2013). Assessment of methods for mapping snow cover from MODIS. 857 Adv in Water Resour, 51:367-380.

858 Roesch A (2006). Evaluation of surface albedo and snow cover in AR4 coupled climate models. J 859 Geophys Res, 111.

860 Saha S, Moorthi S, Pan H-L W, Wang J, Nadiga S, Tripp P, et al. (2010). The NCEP climate forecast system reanalysis. Bull Amer Meteorol Soc, 91:1015-1057.

863 Simulations for Seasonal Mountain Snow in the Upper Colorado River Basin. J Hydrometeorol, $864 \quad 13: 539-556$.

865 Skiles S, Painter T, Deems J, Bryant A, Landry C (2012). Dust radiative forcing in snow of the Upper 866 Colorado River Basin: 2. Interannual variability in radiative forcing and snowmelt rates. Water 867 Resour Res, 48.

868 Smith C, Guttman L (1953). Measurement of internal boundaries in three-dimensional structures by 869 random sectioning. Trans AIME, 5:81-87. 
Sun C, Walker J, \& Houser P (2004). A methodology for snow data assimilation in a land surface model. J Geophys Res , 109, D08108.

Takala M, Luojus K, Pulliainen J, Derksen C, Lemmetyinen J, Kärnä J.-P., et al. (2011). Estimating northern hemisphere snow water equivalent for climate research through assimilation of space-borne radiometer data and ground-based measurements. Remote Sens of Environ, 115:3517-3529.

Tedesco M, Pulliainen J, Takala M, Hallikainen M, Pampaloni P (2004a). Artificial neural networkbased techniques for the retrieval of SWE and snow depth from SSM/I data. Remote Sens of Environ, 90:76-85.

Tedesco M, Kelly R, Foster J, Chang A (2004b). AMSR-E/Aqua Daily L3 Global Snow Water Equivalent EASE-Grids V002. updated daily. Boulder, Colorado USA: National Snow and Ice Data Center, URL http://nsidc.org/data/ae_dysno.

Teschl E, Randeu W, Teschl R (2010). Microwave scattering from ice crystals: how much parameters can differ from equal volume spheres. Adv in Geosci, 25:127-133.

Toure A, Goita K, Royer A, Kim E, Durand M, Margulis S, et al. (2011). A case study of using a multilayered thermodynamical snow model for radiance assimilation. IEEE Trans on Geosci and Remote Sens, 49(8):2828-2837.

Uppala S, Kallberg P, Simmons A, Andrae U, Da Costa Bechtold V, Fiorino M, et al. (2005). The ERA-40 re-analysis. Q J of the Royal Meteorol Soc, 131(612):1961-3012.

Wiesmann A, Mätzler C. (1999). Microwave emission model of layered snowpacks. Remote Sens of Environ, 70(3):307-316.

Wiesmann A, Fierz C, Mätzler C (2000). Simulation of microwave emission from physically modeled snowpacks. Ann of Glaciol, 31(1):397-405.

Yang D, Zhao Y, Armstrong R, Robinson D, Brodzik, M-J (2007). Streamflow response to seasonal snow cover mass changes over large Siberian watersheds. J Geophys Res Earth Surf, 112.

(1) 
900 Table 1 Summary of selected gridded time-series of snow mass or depth.

\begin{tabular}{|c|c|c|c|c|c|c|}
\hline Name & Type & Start Year & End Year & Coverage & Resolution & Reference \\
\hline ERA-40 & Reanalysis & 1957-09 & $2002-08$ & Global & T159 & $\begin{array}{l}\text { Uppala et } \\
\text { al., } 2005\end{array}$ \\
\hline $\begin{array}{l}\text { ERA- } \\
\text { Interim }\end{array}$ & Reanalysis & 1989 & present & Global & $\mathrm{T} 255$ & $\begin{array}{l}\text { Dee et } \\
\text { al.,2011 }\end{array}$ \\
\hline MERRA & Reanalysis & 1979 & Present & Global & $0.5^{\circ} \times 0.66^{\circ}$ & $\begin{array}{l}\text { Rienecker } \\
\text { et al., } 2010\end{array}$ \\
\hline $\begin{array}{l}\text { NCEP- } \\
\text { CFSR }\end{array}$ & Reanalysis & 1979 & Present & Global & T382 & $\begin{array}{l}\text { Saha et } \\
\text { al.,2010 }\end{array}$ \\
\hline JRA-25 & Reanalysis & 1979 & 2004 & Global & T106 & $\begin{array}{l}\text { Onogi et al., } \\
2007\end{array}$ \\
\hline $\begin{array}{l}\text { ECMWF } \\
\text { operational }\end{array}$ & $\begin{array}{l}\text { Offline } \\
\text { model }\end{array}$ & 1987 & Present & Global & T511 & $\begin{array}{l}\text { Drusch et } \\
\text { al., } 2004\end{array}$ \\
\hline $\mathrm{CNC}$ & $\begin{array}{l}\text { Offline } \\
\text { model }\end{array}$ & 1979 & 1997 & $\begin{array}{l}\text { North } \\
\text { America }\end{array}$ & $0.3^{\circ} \times 0.3^{\circ}$ & $\begin{array}{l}\text { Brown et } \\
\text { al., } 2003\end{array}$ \\
\hline Kitaev et al & Observations & 1936 & 1995 & $\begin{array}{l}\text { Former } \\
\text { Soviet } \\
\text { Union }\end{array}$ & $3^{\circ} \times 5^{\circ}$ & $\begin{array}{l}\text { Kitaev et } \\
\text { al., } 2002\end{array}$ \\
\hline $\begin{array}{l}\text { Dyer and } \\
\text { Mote }\end{array}$ & Observations & 1960 & 2000 & $\begin{array}{l}\text { North } \\
\text { America }\end{array}$ & $1^{\circ} \times 1^{\circ}$ & $\begin{array}{l}\text { Dyer and } \\
\text { Mote, } 2006\end{array}$ \\
\hline SNODAS & $\begin{array}{l}\text { Model plus } \\
\text { in-situ } \\
\text { observatinos }\end{array}$ & 2003-09-30 & Present & $\begin{array}{l}\text { Contiguous } \\
\text { United } \\
\text { States }\end{array}$ & $\begin{array}{l}1 \mathrm{~km} \times 1 \\
\mathrm{~km}\end{array}$ & $\begin{array}{l}\text { Carroll et } \\
\text { al., } 2001\end{array}$ \\
\hline $\begin{array}{l}\text { SSMR / } \\
\text { SSM/I }\end{array}$ & Microwave & 1978-11 & 2007-05 & Global & $\begin{array}{l}25 \mathrm{~km} \times 25 \\
\mathrm{~km}\end{array}$ & $\begin{array}{l}\text { Armstrong } \\
\text { et al., } 2005\end{array}$ \\
\hline AMSR-E & Microwave & 2002-06 & 1978-11 & Global & $\begin{array}{l}25 \mathrm{~km} \times 25 \\
\mathrm{~km}\end{array}$ & $\begin{array}{l}\text { Tedesco et } \\
\text { al., 2004b }\end{array}$ \\
\hline
\end{tabular}

901 
Table 2 Chang Sensitivity calculated from the trend in brightness temperature difference for the first

$904100 \mathrm{~mm}$ of Snow Water Equivalent (SWE) for grain diameters of $0.2 \mathrm{~mm}$ to $1.0 \mathrm{~mm}$. The snow and

905 surface properties used are those from Figure 1.

\begin{tabular}{ll}
\hline Grain Diameter $(\mathbf{m m})$ & Chang Sensitivity $\left(\mathbf{m m}_{\mathbf{S W E}} \mathbf{K}^{-1}\right)$ \\
\hline $\mathbf{0 . 2}$ & 14.64 \\
$\mathbf{0 . 4}$ & 4.18 \\
$\mathbf{0 . 6}$ & 2.47 \\
$\mathbf{0 . 8}$ & 1.85 \\
$\mathbf{1 . 0}$ & 1.55 \\
\hline
\end{tabular}

906

907 Table 3 Summary of snow input data for each Intensive Observation Period (IOP) split by Mesoscale 908 Study Area (MSA).

\begin{tabular}{|c|c|c|c|c|c|c|}
\hline & Dates & MSA & Snowpits & $\begin{array}{l}\text { Mean } \\
\text { Depth (cm) }\end{array}$ & $\begin{array}{l}\text { Mean SWE } \\
(\mathrm{mm})\end{array}$ & $\begin{array}{l}\text { Snow } \\
\text { Cover }(\%)\end{array}$ \\
\hline \multirow{3}{*}{ IOP3 } & $20-25^{\text {th }} \mathrm{Feb}$ & North Park & 115 & 14.0 & 23.1 & 100 \\
\hline & 2003 & Rabbit Ears & 18 & 225.6 & 580 & 100 \\
\hline & & Fraser & 48 & 77.3 & 189 & 100 \\
\hline \multirow{3}{*}{ IOP4 } & 26-30 ${ }^{\text {th }}$ Mar & North Park & 68 & 5.3 & 9.6 & 57 \\
\hline & 2003 & Rabbit Ears & 44 & 229.0 & 758 & 100 \\
\hline & & Fraser & 48 & 143.2 & 381 & 92 \\
\hline
\end{tabular}

909

910

911

912

913

914

915

916

917 
918 Table 4 Average brightness temperature difference for each Intensive Observation Period (IOP) as

919 simulated by inverting the Chang algorithm, using different numbers of layers in the Helsinki

920 University of Technology (HUT) microwave emission model, and the average retrievals for Advanced

921 Microwave Scanning Radiometer-Earth Observing System (AMSR-E) and Special Sensor Microwave

922 Imager (SSM/I).

\begin{tabular}{lcc}
\hline & & $\mathbf{T}_{\mathbf{B}}(\mathbf{1 9 H})-\mathbf{T}_{\mathbf{B}}(\mathbf{3 7 H})(\mathbf{K})$ \\
\hline Chang & IOP3 & IOP4 \\
1-layer & 18.58 & 24.72 \\
2-layer & 20.23 & 13.86 \\
3-layer & 20.19 & 13.18 \\
4-layer & 20.24 & 13.31 \\
5-layer & 20.21 & 13.35 \\
N-layer & 20.23 & 13.32 \\
AMSR-E & 20.24 & 13.46 \\
SSM/I & 16.03 & 15.71 \\
\hline
\end{tabular}

923

924

925

926

927

928

929 


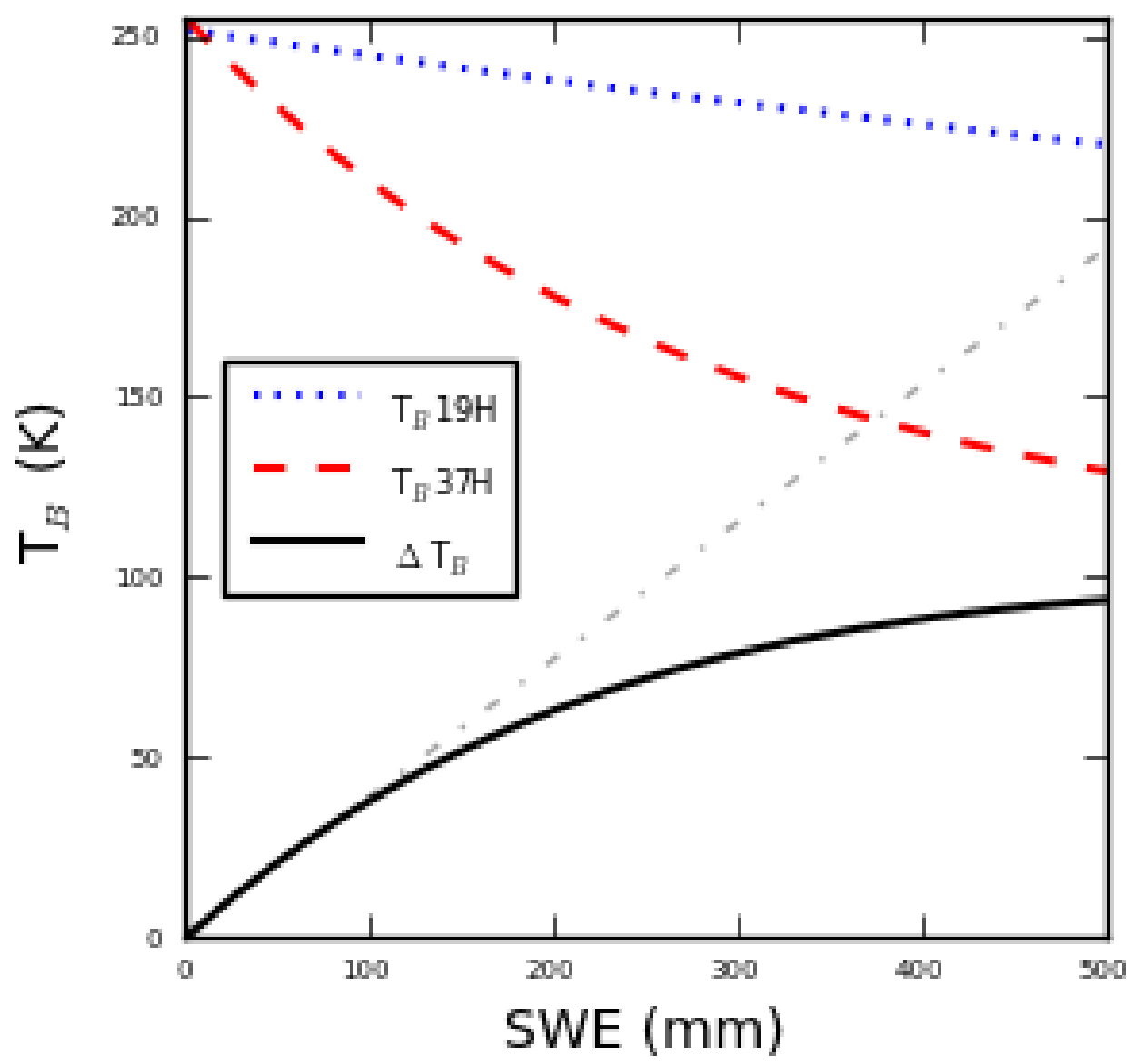

931

932 Figure 1 Simulated brightness temperature for a homogeneous snowpack as a function of Snow

933 Water Equivalent (SWE) at the Advanced Microwave Scanning Radiometer for Earth Observing

934 System (AMSR-E) channels near $19 \mathrm{GHz}$ and $37 \mathrm{GHz}$ horizontal polarisation. Snowpack properties

935 are those average of Cold Land Processes Experiment (CLPX) snowpits where depth was $<120 \mathrm{~cm}$.

936 Density of $170 \mathrm{~kg} \mathrm{~m}^{-3}$, grain size of $0.53 \mathrm{~mm}$, snow temperature $-4.6{ }^{\circ} \mathrm{C}$ and ground temperature -1.5

$937{ }^{\circ} \mathrm{C}$. The upper dashed lines show the brightness temperature at $19 \mathrm{H}$ and $37 \mathrm{H}$ as labelled, the solid line

938 is the difference brightness temperature between the two (see Equation (1)), offset by $3 \mathrm{~K}$ to ensure

939 that the value is zero when no snow is present. The straight dashed line is the best fit to the first 100

$940 \mathrm{~mm}$ of SWE. 


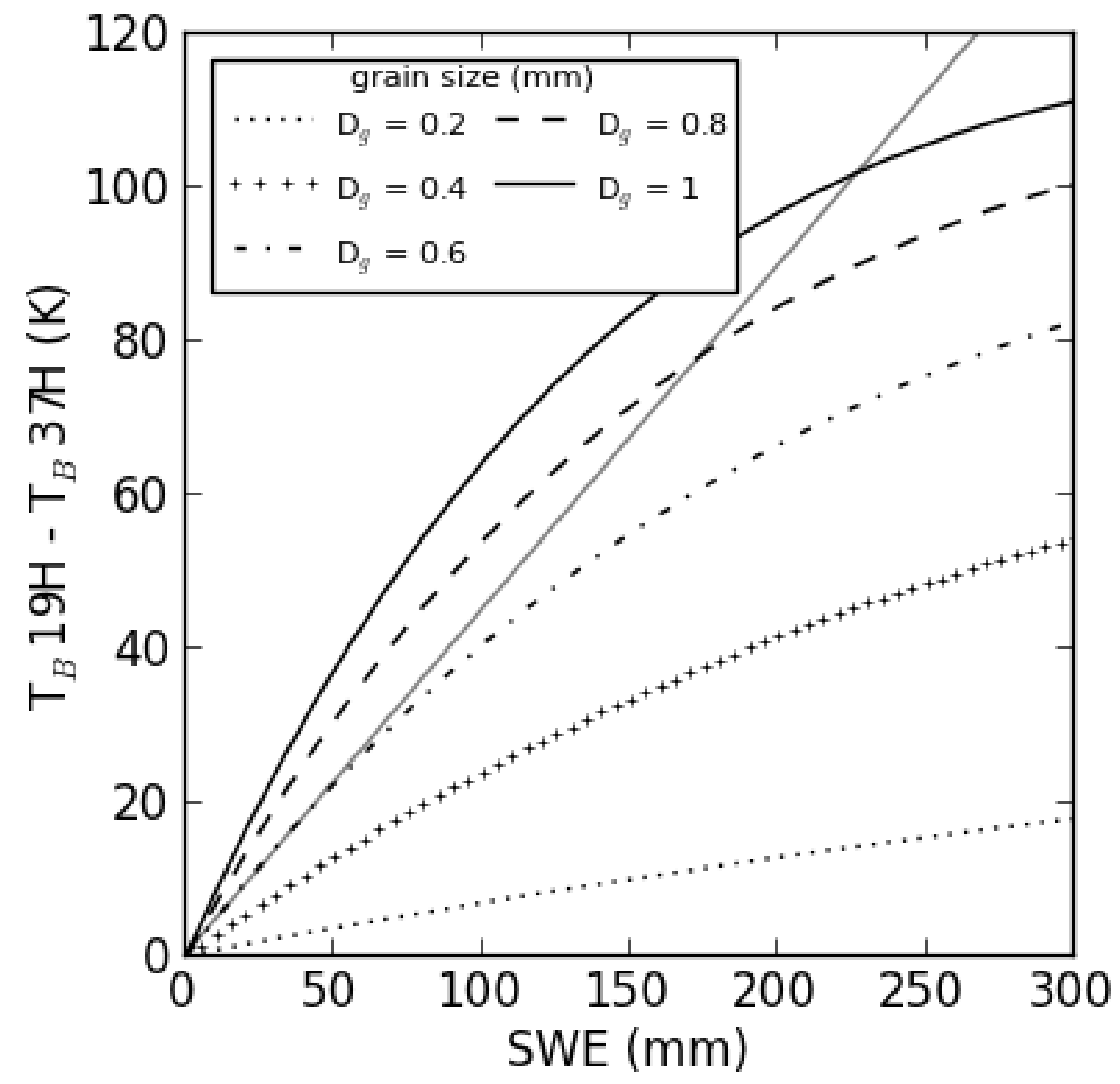

941

Figure 2 Brightness temperature difference as a function of Snow Water Equivalent (SWE) for the

943 same snow properties as in Figure 1, except that grain diameter is varied from $0.2 \mathrm{~mm}$ to $1.0 \mathrm{~mm}$ in

$9440.2 \mathrm{~mm}$ increments. The caption (top left) indicates which line style refers to each grain size value.

945 The shaded straight line is the linear best fit to the first $50 \mathrm{~mm}$ SWE worth of the central grain size 946 value.

947

948

949

950

951 


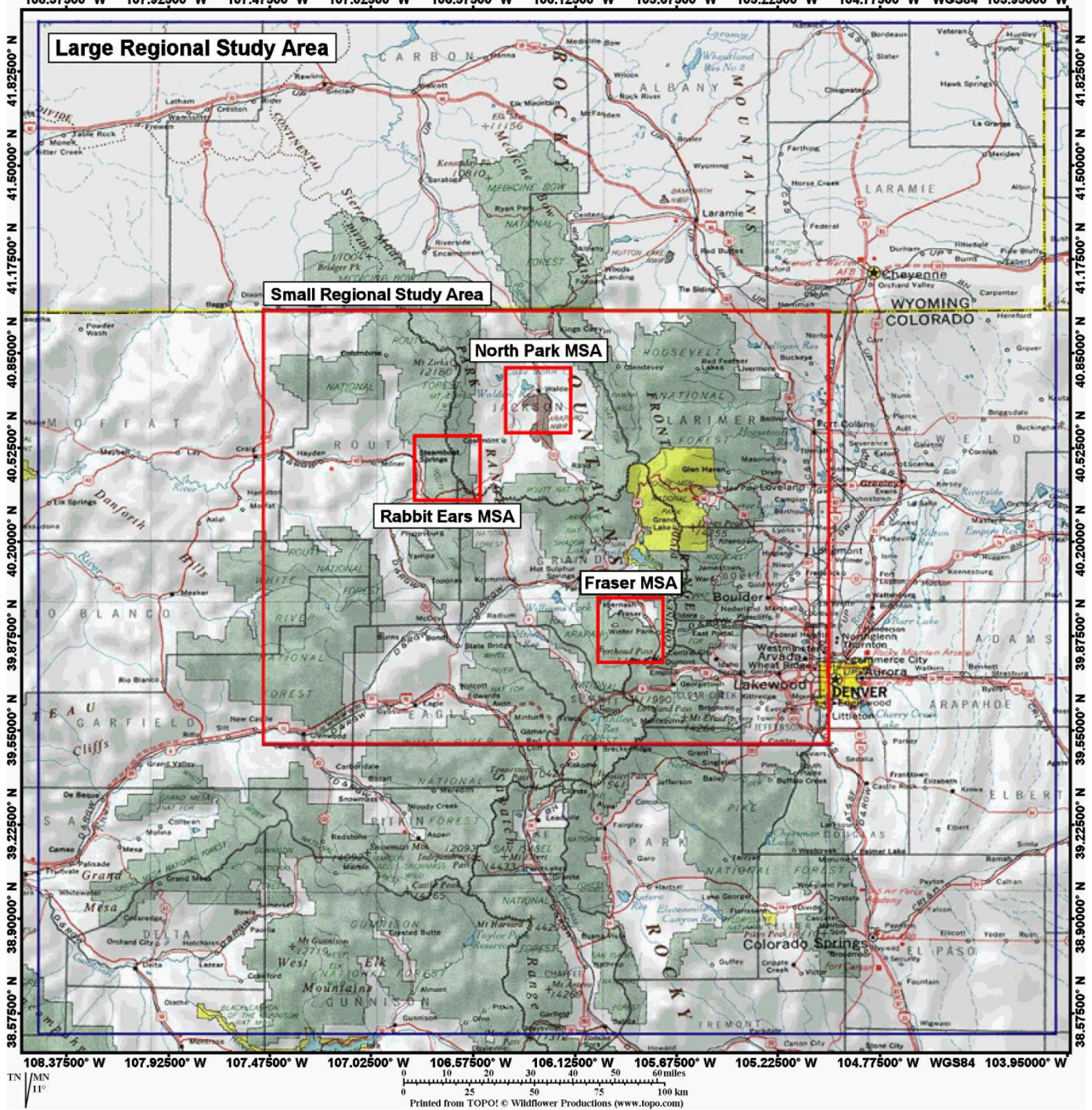

954 Figure 3 Map of Cold Land Processes Experiment (CLPX) area showing the Mesoscale Study Areas

955 (MSAs) in which the snowpits were dug. (after http://www.nohrsc.nws.gov/ cline/clpx.html) 


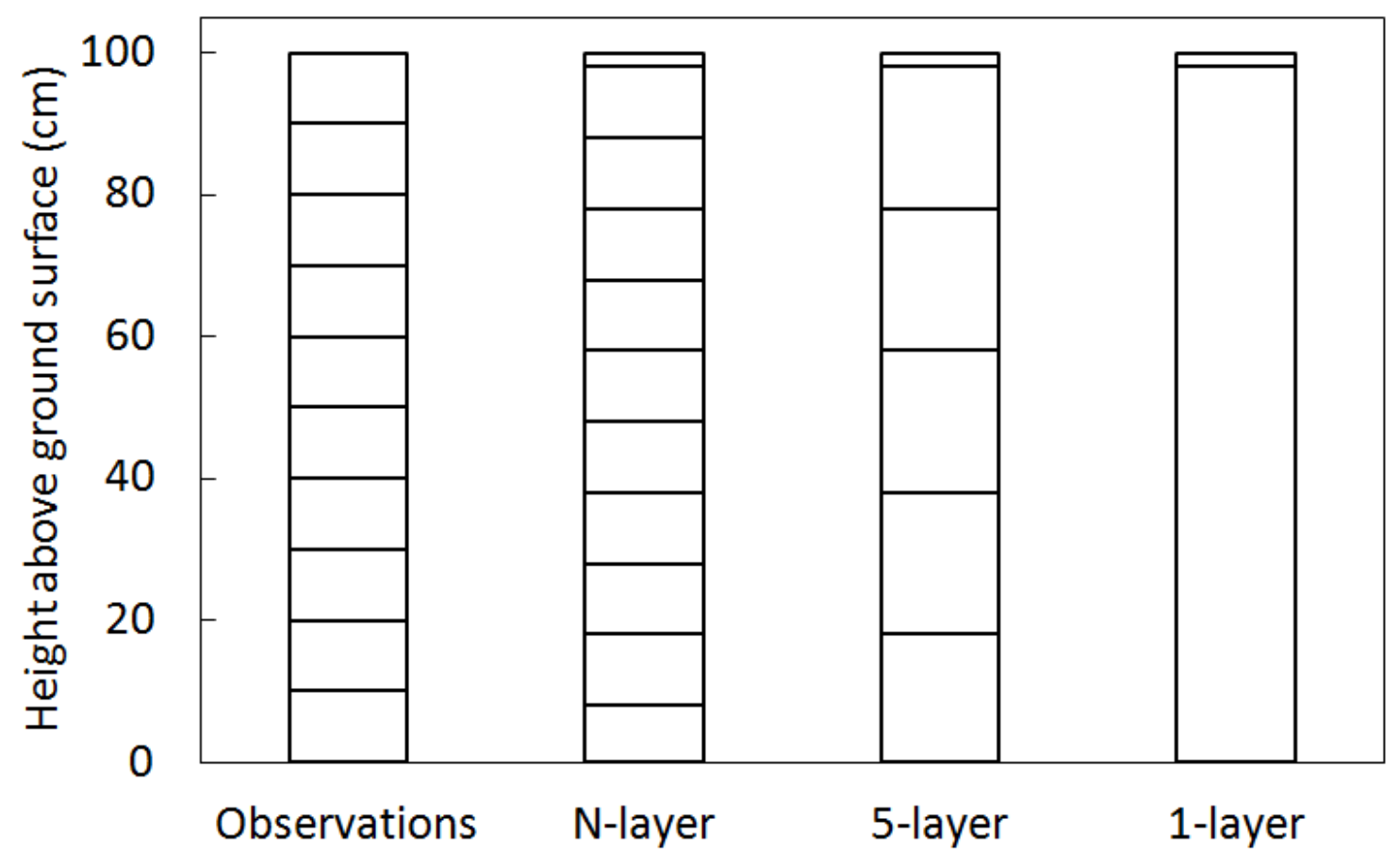

962 Figure 4 Example of the how snowpit data were restructured. The left hand bar represents the

963 observation profile where depth and temperature are recorded for each $10 \mathrm{~cm}$ of the snow. The N-

964 layer resampling maintains $10 \mathrm{~cm}$ layer thicknesses but adds a $2 \mathrm{~cm}$ interaction layer at the surface, as

965 is common in a number of Land Surface Models' snow schemes. The other layering schemes apply a 2

$966 \mathrm{~cm}$ top layer and then evenly split the remaining snow depth, with density, snow and grain size mass-

967 weighted according to the observations. All layer structures from 1 to 5 inclusive were calculated, but only 1 and 5 are shown here for simplicity. 


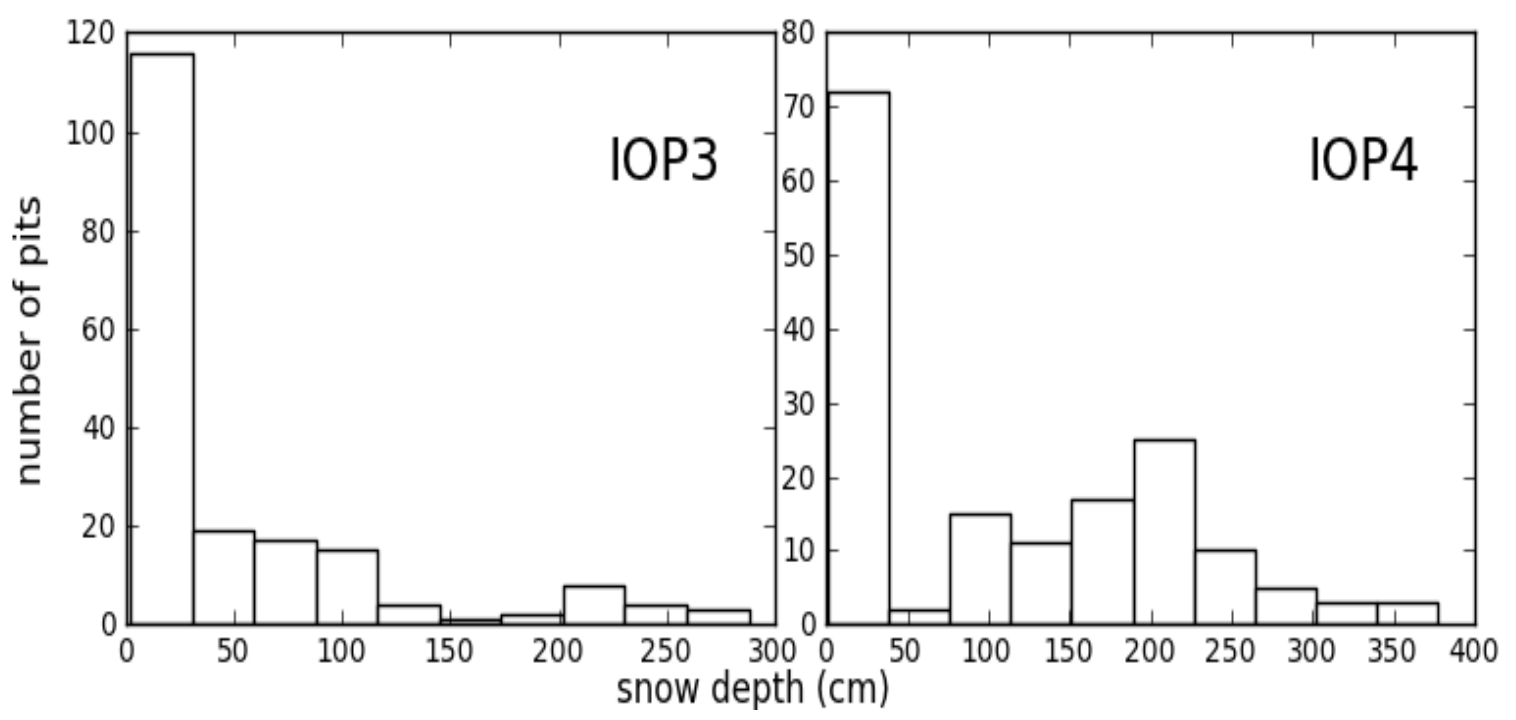

972 Figure 5 Count of snowpits by depth for each Intensive Observation Period (IOP).
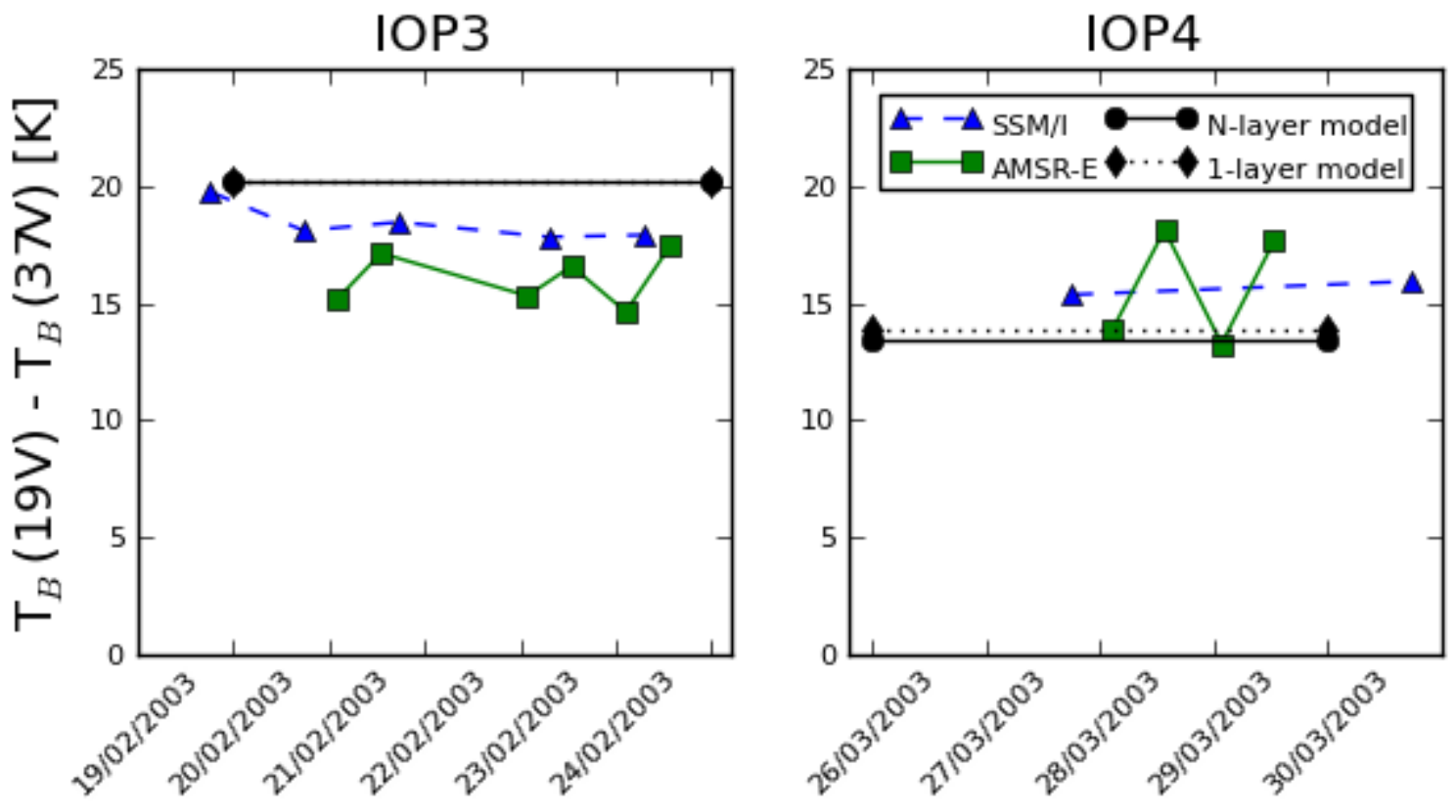

976 Figure 6 Brightness temperature difference retrievals for Special Sensor Microwave Imager (SSM/I)

977 (triangles), Advanced Microwave Scanning Radiometer-Earth Observing System (AMSR-E)

978 (squares) and the average simulated snowpit data processed through the Helsinki University of

979 Technology (HUT) microwave emission model. HUT simulations are provided for the N-layer case

980 (circles) and for a single layer case where all properties were averaged to one layer (triangles).

981 Caption in bottom right identifies marker shapes and line styles. 


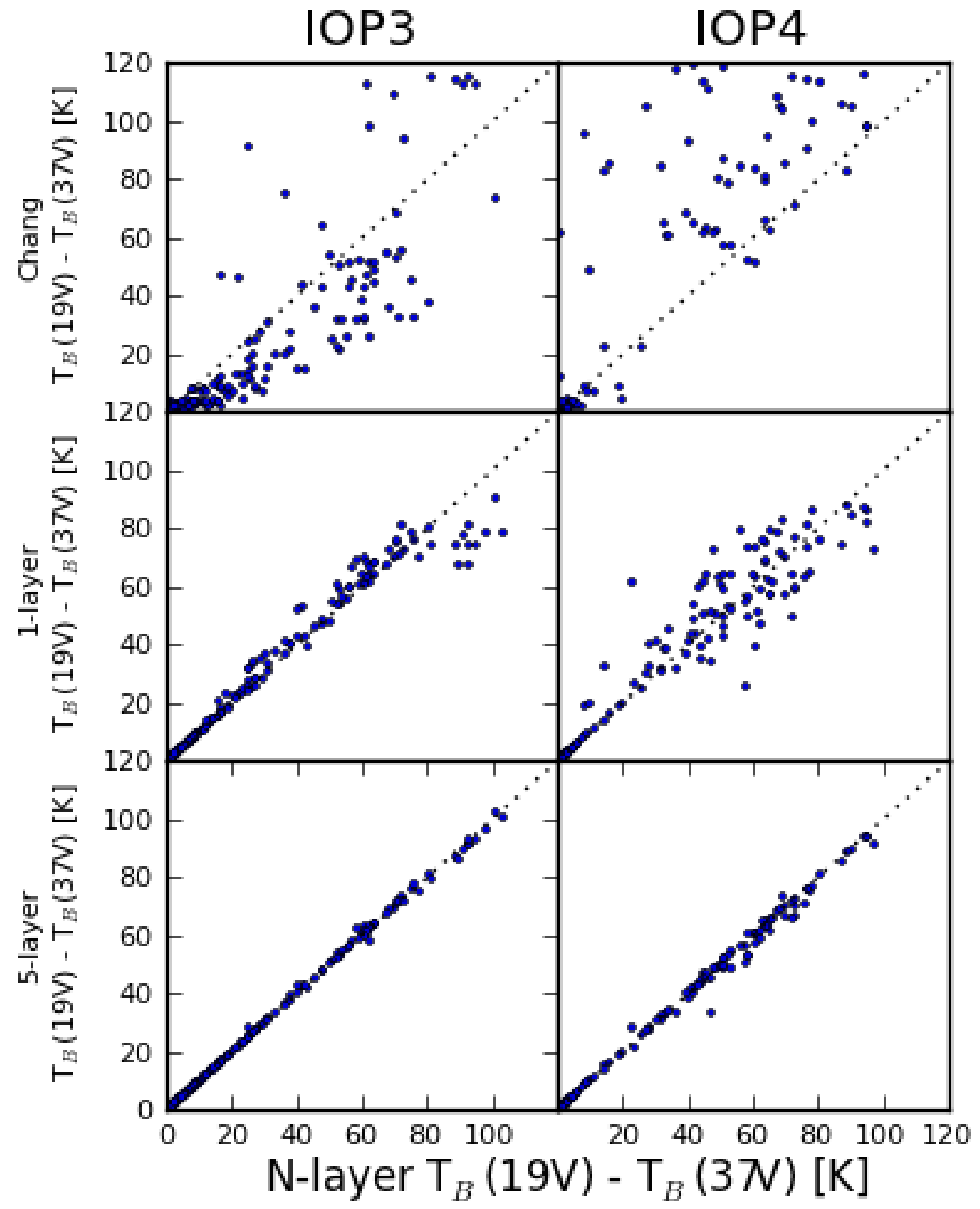

982

983 Figure 7 Brightness temperature differences simulated for each pit during Intesive Observation

Period (IOP) 3 (left) and IOP4 (right). The ordinate in each case is the simulated brightness temperature difference using the N-layer model, and the abscissa shows the Chang output (top), 1layer Helsinki University of Technology model (HUT) output (centre) and 5-layer HUT (bottom) output as labelled. The dotted line is the one-to-one correspondence line. 


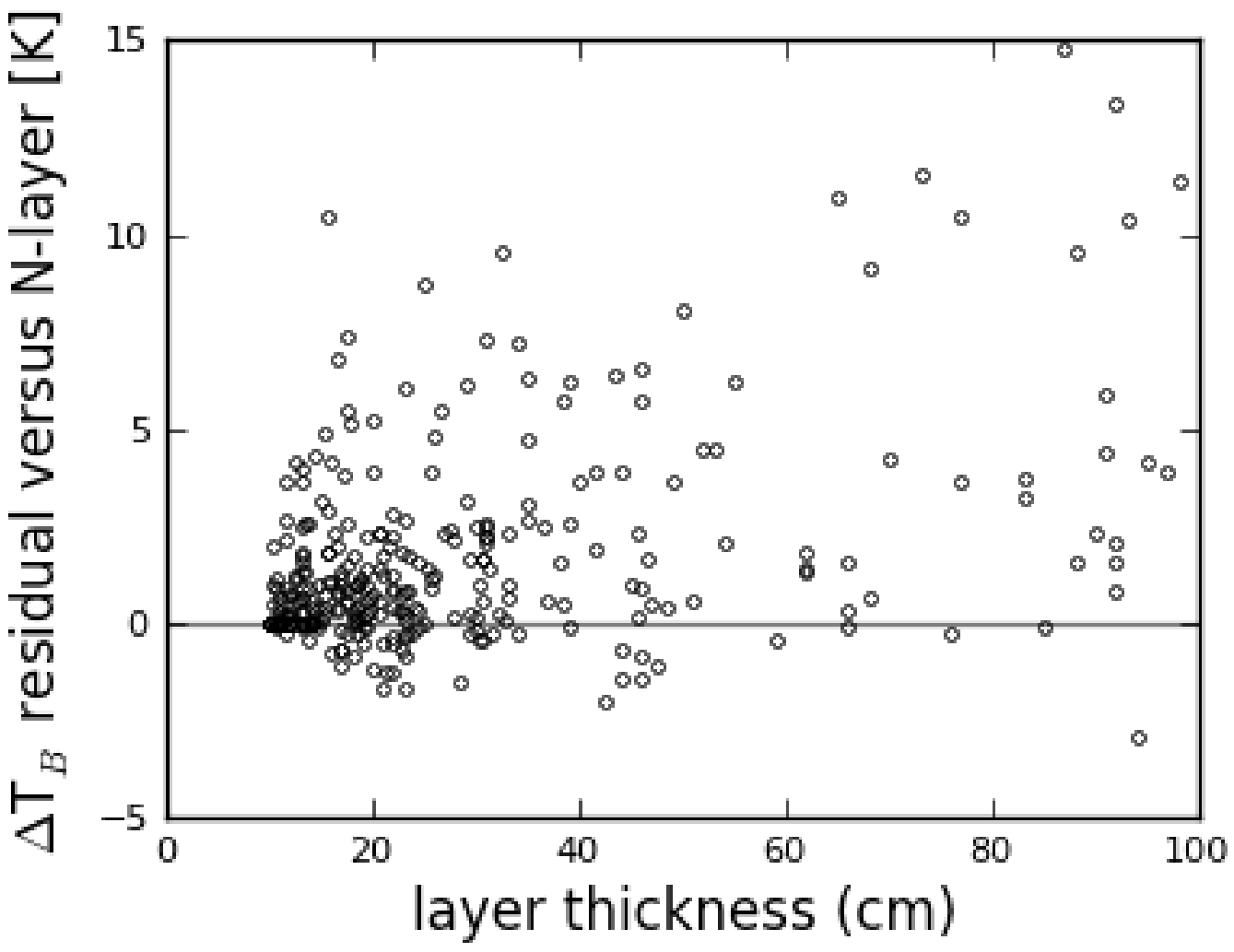

994 Figure 8 Residual between brightness temperature difference simulated for models with layer 995 thickness $>10 \mathrm{~cm}$ versus the $10 \mathrm{~cm}$ layer simulation, and plotted as a function of this bulk-layer 996 thickness. All data represented as open circles.

997

998

999 

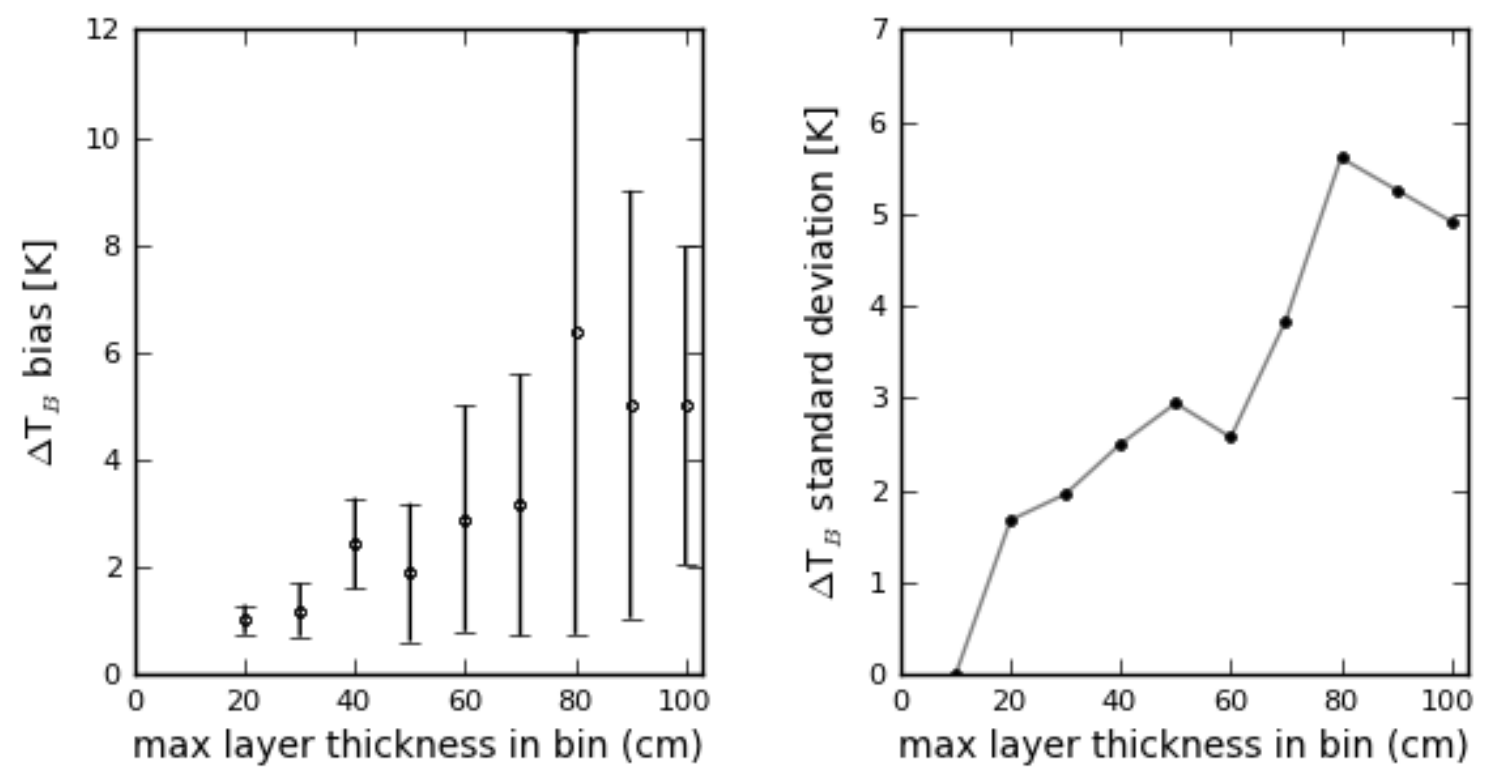

1001 Figure 9 Bias in simulated brightness temperature difference for snow profiles of thicker layers, 1002 relative to an $\mathrm{N}$-layer model with $10 \mathrm{~cm}$ layer thicknesses (left), where error bars are 2-sigma (left). 1003 The standard deviation of brightness temperature difference relative to an N-layer model is quantified 1004 as a function of layer size (right), with an approximately linear increase in simulated brightness 1005 temperature difference error as snow stratigraphy is simplified into thicker layers. 


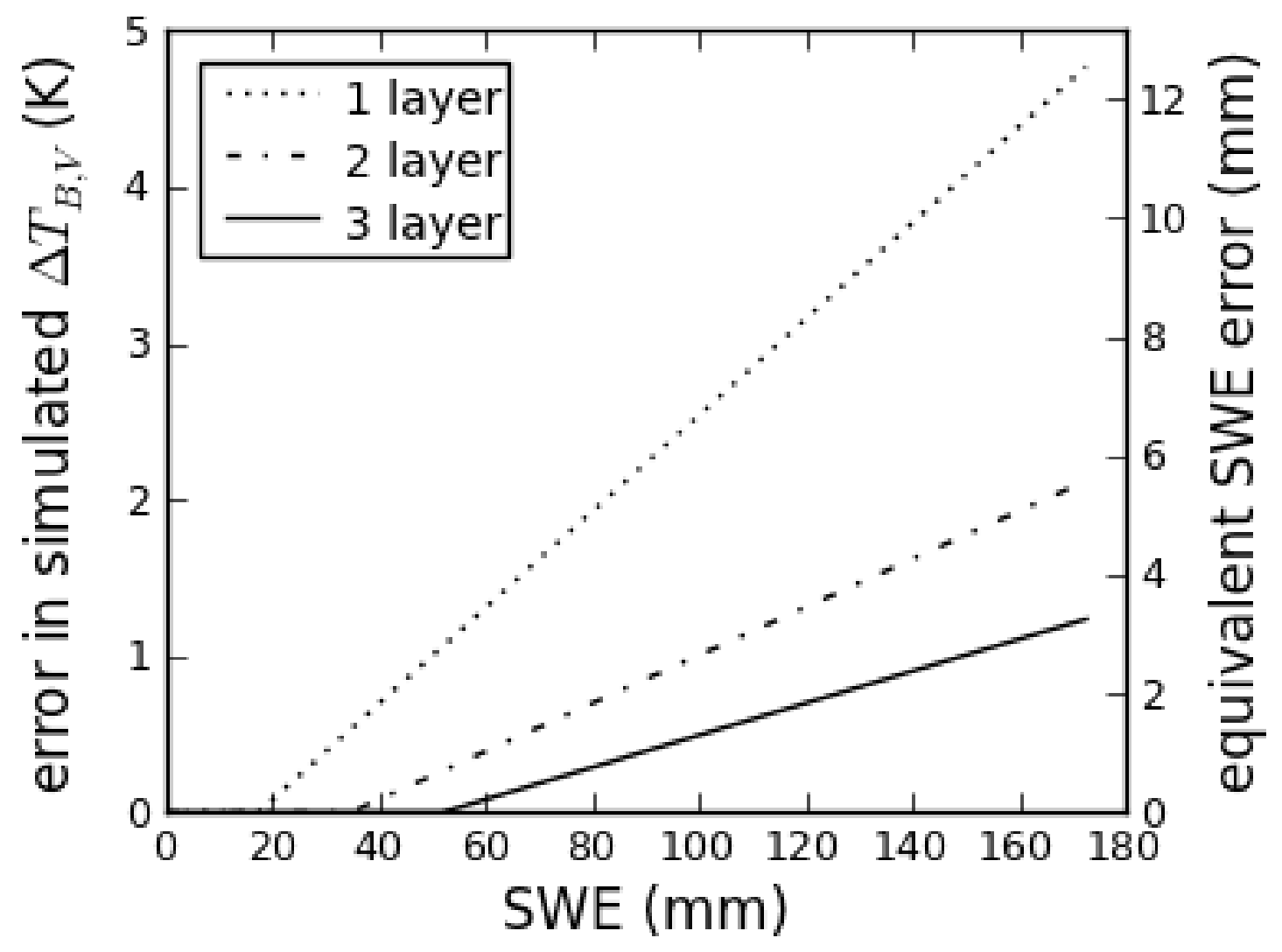

1006

1007 Figure 10 Absolute error in SWE introduced via simplification of the Cold Land Processes

1008 Experiment (CLPX) pit stratigraphy from N-layers to fewer layers, as a function of total Snow Water 1009 Equivalent (SWE). Lines represent output using a one- (dotted line), two- (dashed line) or three-layer 1010 (solid line) snow profile.

1011

1012

1013 